Portland State University

PDXScholar

\title{
Disfluencies in Normal Four-Year-Old Alaska Native and Caucasian Children
}

Annette Cameron O'Connell

Portland State University

Follow this and additional works at: https://pdxscholar.library.pdx.edu/open_access_etds

Part of the Speech Pathology and Audiology Commons Let us know how access to this document benefits you.

\section{Recommended Citation}

O'Connell, Annette Cameron, "Disfluencies in Normal Four-Year-Old Alaska Native and Caucasian Children" (1989). Dissertations and Theses. Paper 3901.

https://doi.org/10.15760/etd.5785

This Thesis is brought to you for free and open access. It has been accepted for inclusion in Dissertations and Theses by an authorized administrator of PDXScholar. Please contact us if we can make this document more accessible: pdxscholar@pdx.edu. 
AN ABSTRACT OF THE THESIS OF Annette Cameron o'Connell for the Master of Science in Speech Communication presented April 26, 1989 .

Title: Disfluencies in Normal Four-Year-old Alaska Native and Caucasian Children.

APPROVED BY THE MEMBERS OF THE COMMITTEE:

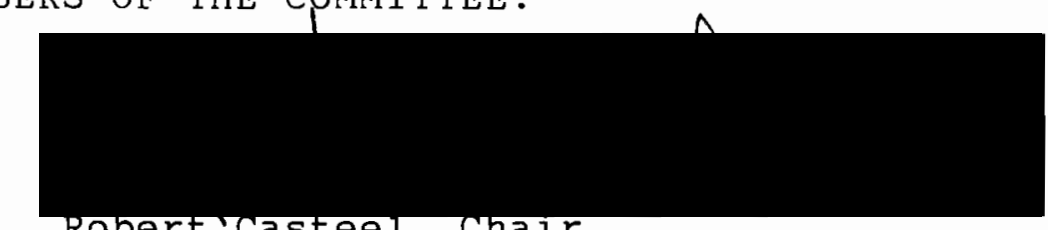

Robert casteel, chair

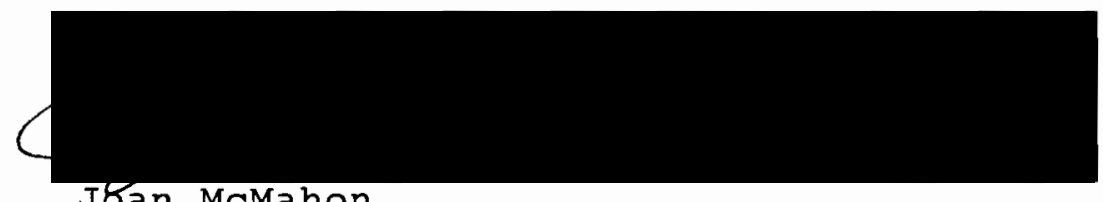

Joan McMahon

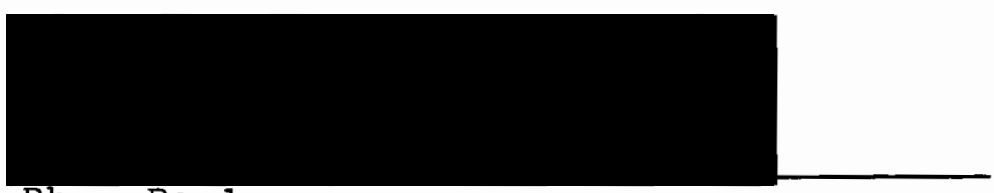

Rhea Paul

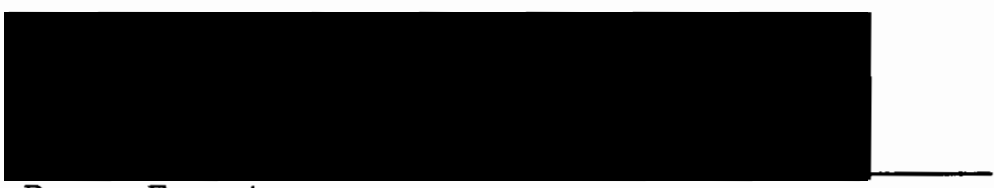

Dean Frost

Normative data on normal disfluency of Alaska Native children appears to be needed and without normative data it is difficult to differentiate disorder from normal ethnic variability. The majority of disfluency research has been done on Caucasian children and it appears that there has not been research done to ascertain the appropriateness of using 
Caucasian normative data to assess disfluencies of Alaska Native children.

The purpose of this study was to compare the frequency of occurrence of specific speech disfluencies in 4-year-old Alaska Native children to those of 4-year-old Caucasian children. Specifically, eight disfluency types were investigated: part-word repetition, word repetition, phrase repetition, interjection, revision-incomplete phrase, disrhythmic phonation, tense pause, and intrusive schwa. The questions addressed in the study were:

1. Do 4-year-old Alaska Native children exhibit a higher frequency of disfluencies than 4-year-old Caucasian children?

2. Do 4-year-old Alaska Native children exhibit a greater frequency of specific disfluencies, in terms of part-word repetition, word repetition, phrase repetition, interjection, revision-incomplete phrase, disrhythmic phonation, tense pause, or intrusive schwa than 4-year-old Caucasian children?

3. Do 4-year-old Alaska Native and Caucasian children exhibit a higher frequency of low risk disfluency types (word repetition, phrase repetition, interjection, and revision-incomplete phrase) when compared to high risk disfluency types (part-word repetition, disrhythmic phonation, tense pause, and intrusive schwa)? 
Thirty-four normal preschool children comprised the subjects of this study; 17 4-year-old Alaska Native children and 17 4-year-old Caucasian children. All the children were selected from the Kenai Peninsula and passed the selection criteria. Spontaneous speech samples were obtained and recorded from each of the subjects. Utilizing an analysis of variance, no statistically significant difference at the .05 level existed between the two racial groups.

The results yielded the following conclusions:

1. The 4-year-old Caucasian children did not exhibit a higher frequency of disfluencies than 4-year-old Alaska Native children.

2. There was no statistically significant difference in the frequency of occurrence of part-word repetition, word repetition, phrase repetition, interjection, revisionincomplete phrase, disrhythmic phonation, tense pause, or intrusive schwa exhibited by the two racial groups of normal children.

3. Both groups evidenced higher frequencies of low risk disfluency types (word repetition, phrase repetition, interjection, and revision-incomplete phrase) when compared to high risk disfluency types (part-word repetition, disrhythmic phonation, tense pause, and intrusive schwa).

The results of the current study indicate that interjection, revision-incomplete phrase, word repetition, and phrase repetition are the most common types of disfluencies occurring in the speech of 4-year-old Alaska Native and 
Caucasian children. Part-word repetition, disrhythmic phonation, tense pause, and intrusive schwa were the least frequently occurring types of disfluencies observed in Alaska Native and Caucasian 4-year-old children. However, there was a subgroup of Alaska Native children in the fourth quartile who were markedly more disfluent and their speech accounted for most of the high risk types of disfluencies found in the total sample of Alaska Natives. 
DISFLUENCIES IN NORMAL FOUR-YEAR-OLD ALASKA NATIVE AND CAUCASIAN CHILDREN

by

ANNETTE CAMERON O'CONNELL

A thesis submitted in partial fulfillment of the requirements for the degree of

\author{
MASTER OF SCIENCE \\ in \\ SPEECH COMMUNICATION \\ with an emphasis in \\ SPEECH-LANGUAGE PATHOLOGY
}

Portland State University

1989 
TO THE OFFICE OF GRADUATE STUDIES:

The members of the Committee approve the thesis of Annette Cameron O'Connell presented April 26, 1989.

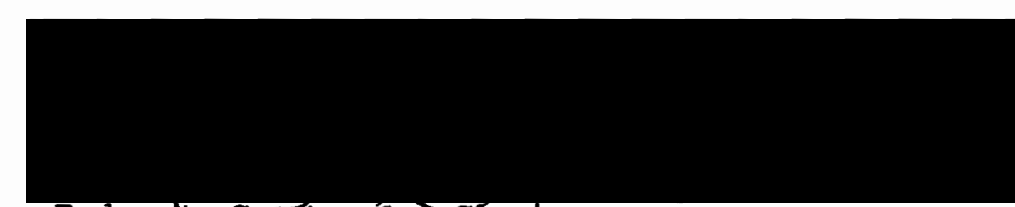

Robert Casteel, Chair

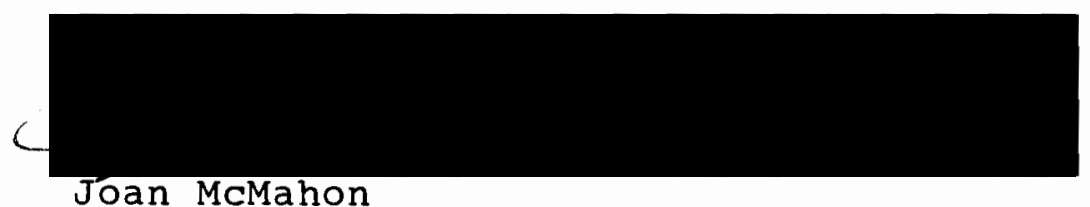

Joan McMahon
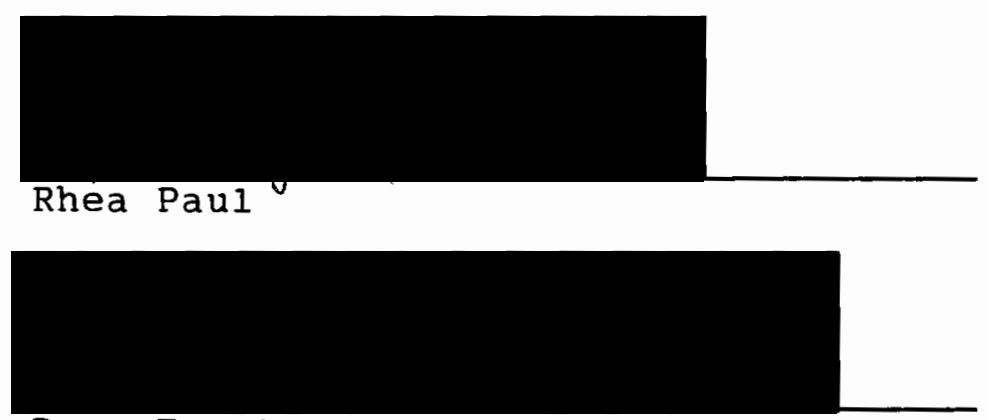

Dean Frost

APPROVED :

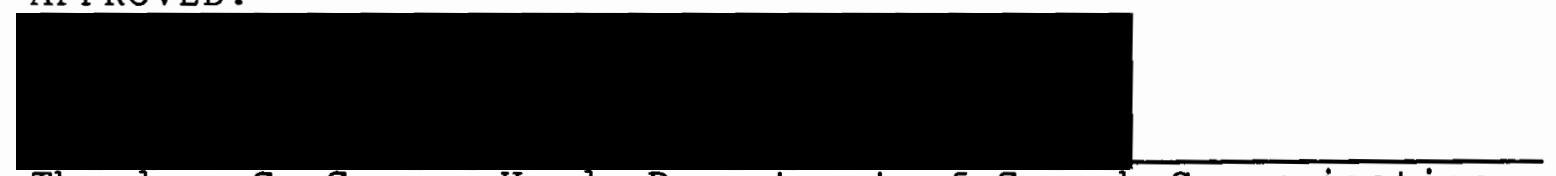

Theodore G. Grove, Head, Department of Speech Communication

Bernard Ross, Vice Provost for Graduate studies 


\section{ACKNOWLEDGMENTS}

There are many who were instrumental in this project and without whose help I could not have finished:

My husband Robert, whose love, support, and sacrifice made this all possible;

My daughter Cameron, who gave up so much time with her mother to help in ways only a 6-year-old can help;

Dr. Casteel, my thesis director: Thank you;

My parents, whose encouragement and help was always available;

My Lord Jesus Christ, my foundation, whose gentle leading, love, and patience is unending. 
TABLE OF CONTENTS

PAGE

ACKNOWLEDGMENTS . . . . . . . . . . . . . . . . . . i ii

LIST OF TABLES . . . . . . . . . . . . . . . . . . vii

LIST OF FIGURES . . . . . . . . . . . . . . . . . . . viii

CHAPTER

I INTRODUCTION AND STATEMENT OF PURPOSE . . . . . 1

Introduction . . . . . . . . . . . . . 1

Statement of Purpose . . . . . . . . . 2

Definition of Terms . . . . . . . . 3

I I REVIEW OF THE LITERATURE . . . . . . . . . . 7

Rationale for Examining Normal

Disfluencies in Four-Year-01d

Children .............. 7

Rationale for Examining Normal

Disfluency Rates . . . . . . . . . . . 8

Normal Fluency Rates and Types... . . 10

Frequency

Types

Normal Disfluency Rates and Types

at Discrete Age Levels . . . . . . 13

Three-Year-01ds

Four-Year-olds

Five-Year-olds

Incipient stuttering Characteristics . . .

Frequency

Types

High Risk-Low Risk Fluency Types . . . . 
Theories of Disfluency Which Relate Specifically to a Cultural and Racial Group

subjects . . . . . . . . . . . .

Subject Selection Procedures . . . . . .

Speech Sample Procedures.

Scoring procedures . . . . . . . . .

Reliability . . . . . . . . . . . . .

Data Analysis .......... . . 35

IV

$$
\text { RESUT }
$$

Results

Descriptive Statistics

Discussion . . . . . . . . . . . . . .

$\mathrm{V}$ SUMMARY AND IMPLICATIONS . . . . . . . . .

Summary

Implications

Research

REFERENCES

APPENDIX

A Letter of Introduction to Parents or Caregiver

B Form Indicating Willingness to Participate.

C Demographic Questionnaire and Consent Form.

D List of Stimuli... . . . . . . . . 68

E Rules for Calculating 300 Word Samples . . . 69

F Rules for Identifying Disfluencies . . . . 
G Coding Symbols . . . . . . . . . . . . . .

$H \quad$ Instructions for selection of Content Transcripts for Reliability Testing . . .

I Instructions to Reliability Judges . . . . . 


\section{LIST OF TABLES}

TABLE

PAGE

I Summary of the Analysis of Variance F-Test for the Effect of Race on the Disfluencies Per 300 Words of Eight Individual Types of Disfluencies and Their Total . . . . . .

II Total High Risk Disfluencies of Alaska Native Children Per 100 Words Spoken Divided into Quartiles . . . . . . . . . . . .

II Total High Risk Disfluencies of Caucasian 4-Year-01d Children Per 100 Words Spoken Divided into Quartiles . . . . . . . . .

IV A Split one-Half Comparison, Collapsing Alaska Native (AN) and Caucasian (C) 4-Year-old Children by Rank Order of Disfluency • • • . • • . . • • • • • •

V Rank Order, Total, Means, and Standard

Deviations for Seven Individual Types of Disfluencies Per 100 Words Spoken for 4-Year-old Caucasian and Alaska Native

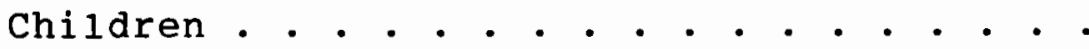




\section{LIST OF FIGURES}

FIGURE

PAGE

1. Type and Frequency Display for Estimating Abnormality of Disfluency . . . . . . .

2. The Relative Frequency of High Risk and Low Risk Disfluency Types in Speech Samples of 17 Alaska Native 4-Year-01d Children . • • • . . . • • . . • • • •

3. The Relative Frequency of High Risk and Low Risk Disfluency Types in Speech Samples of 17 Caucasian 4-Year-01d Children . . . . . . . . . . . . . . .

4. Mean Frequency of Disfluency Per Quartile for Alaska Native and Caucasian 4-Year-old Children . . . . . . . . .

5. Number of Alaska Native and Caucasian Children Found in High Frequency and Low Frequency Categories, When Divided at the Median . . . . . . . . . . . . 
CHAPTER I

INTRODUCTION AND STATEMENT OF PURPOSE

INTRODUCTION

Normative data on speech and language development of the native population of Alaska is apparently nonexistent. Without normative data it is difficult to differentiate disorder from normal ethnic variability. Specifically, speechlanguage pathologists need descriptive data regarding normal disfluency in the native population. Normative fluency data at discrete age levels would aid speech-language pathologists in differentiating developmental disfluency from incipient stuttering in Native Alaska children.

The majority of disfluency research has been conducted on Caucasian children. From these studies it is apparent that the characteristics of normal disfluency and incipient stuttering overlap, making differential diagnosis difficult (Wingate, 1964). Most children between the onset of speech and 6-years-of-age, go through a period of normal disfluency (Van Riper, 1971) and the majority of these nonfluent children spontaneously recover (Andrews, Craig, Feyer, Hoddinott, Howie, and Neilson, 1983).

Early studies on normal disfluencies of 4-year-old Caucasian children revealed that at this age the frequency of 
repetition begins to decline (Davis, 1939; Branscom, Hughes, and oxtoby, 1955). A more recent study (Haynes and Hood, 1977 ) indicates that the total frequency of disfluency of this age group is relatively the same as that of 6-and 8-yearolds. Studies conducted by Haynes and Hood (1977), Wexler (1982), and Wexler and Mysak (1982) find that revisions or revision-incomplete phrases, and interjections are the most common types of disfluencies observed in the speech of 4-year-olds.

There were no data found on normal disfluencies of native Alaskans. There is a need to assess the appropriateness of applying normative data from Caucasian children to Alaska Native children.

\section{STATEMENT OF PURPOSE}

The purpose of this study was to compare the frequency of occurrence of specific speech disfluencies in 4-year-old Caucasian children to those of 4-year-old Alaska Native children. Specifically, eight disfluency types were investigated: part-word repetition, word repetition, phrase repetition, interjection, revision-incomplete phrase, disrhythmic phonation, tense pause, and intrusive schwa. The questions addressed in the study were:

1. Do 4-year-old Alaska Native children exhibit a higher frequency of disfluencies than 4-year-old Caucasian children? 
2. Do 4-year-old Alaska Native children exhibit

a greater frequency of specific disfluencies, in terms of part-word repetition, word repetition, phrase repetition, interjection, revisionincomplete phrase, disrhythmic phonation, tense pause, or intrusive schwa than 4-year-old Caucasian children?

3. Do 4-year-old Alaska Native and Caucasian children exhibit a higher frequency of low risk disfluency types (word repetition, phrase repetition, interjection, and revision-incomplete phrase) when compared to high risk disfluency types (part-word repetition, disrhythmic phonation, tense pause, and intrusive schwa)?

For this study the dependent variable was frequency of speech disfluencies. To all three of these questions, the null hypothesis states that there will be no difference between the Alaska Native children and the Caucasian children.

\section{DEFINITION OF TERMS}

The following operational definitions are partially taken from the Portland State University protocol for disfluency study (Christianson, 1987).

1. Culture: attitudes, beliefs, and life styles of a group of people. When these are in common they are homogeneous and comprise a cultural group (Leith, 1986). 
2. Disfluency: interruption in normal flow of speech, which is characterized by involuntary, audible or silent, repetitions or prolongations (Van Riper, 1971; Wingate, 1964).

3. Disrhythmic phonation: refers to audible or silent continuation of a sound or articulatory posture which is of such excessive duration as to interrupt the rhythmic flow of speech. This disfluency occurs within words and includes broken words and sound prolongations (Williams, Silverman, and Kools, 1968).

4. Eugenics: the movement devoted to improving the human species through the control of hereditary factors in mating.

5. Frequency: the number of disfluencies per 100 words of speech (Riley, 1972).

6. Grammatical pause: silent pause that occurs between grammatical junctures (DeJoy and Gregory, 1985).

7. Incipient stutterer: an individual who is beginning to demonstrate disfluent behavior that is not within normal limits (Adams, 1977). This type of individual may not recover spontaneously and may require intervention for the development of fluent speech. Typically characterized by tense pause, intrusive schwa, part-word repetition, disrhythmic phonation, and/or a high frequency of disfluencies which distract the 1 istener. (PSU protocol.)

8. Interjection: extraneous sounds such as "uh, " "er," "well," and "um" (Johnson 1961). Also referred to as "stallers" by Egland (1955). 
9. Intrusive schwa: refers to the presence of the neutral schwa vowel intruding on the intended vowel. Example: "tuh-tuh-table" (Van Riper, 1971).

10. Nonfluency: interruption in the normal flow of speech. Can refer to normal disfluencies and stuttering. (PSU protocol.)

11. Normal disfluency: interruption in the normal flow of speech. Typically characterized by word repetition, interjection, revision-incomplete phrase, phrase repetition, and/or a low frequency of disfluencies that do not distract the 1istener. (PSU protocol.)

12. Part-word repetition: the repetition of a sound or syllable unit which is less than the entire word. For example, "b-b-boy" is a sound repetition and "ta-ta-table" is a syllable repetition. (PSU protocol.)

13. Parallel talk: is an individual commenting on what a child is doing perceiving, or feeling, and also allowing moments of silence, while playing with the child, to encourage the child to verbalize (Emerick and Hatten, 1979).

14. Phrase repetition: unintentional repetitions of two or more words involving no modification or revision of the content. The sentence "He drove, he drove, he drove home" contains two units of phrase repetition (Johnson, 1959).

15. Repetition instance: refers to the occurrence of a part-word, word, or phrase repetition, regardless of the number of times the part-word, word, or phrase is reiterated. Example: "She, she, she was g-going" contains one instance 
of word repetition and one instance of part-word repetition (Johnson, 1961).

16. Repetition unit: refers to the number of times a part-word, word, or phrase is repeated, not including the most complete form. Example: "ta-ta-ta-table" contains one repetition instance and three repetition units (Johnson, 1961).

17. Revision-incomplete phrase: refers to modifications of a word or phrase as to its pronunciation, grammatical form, or content which is not completed (Johnson, 1961). "Because the doggie- and Daddy went home to eat" has an example of a revision-incomplete phrase.

18. Stuttering: refers to a disturbance in the fluency and timing pattern of speech that is not within normal limits. Typically characterized by tense pause, intrusive schwa, part-word repetition, disrhythmic phonation, and/or a high frequency of disfluencies that distract the listener. (PSU protocol.)

19. Tense pause: a disfluency judged to exist before or between part-words, words, and nonwords (interjections) when at the point in question there are barely audible manifestations of heavy breathing or muscular tightening (Williams et al., 1968).

20. Ungrammatical pause: silent pause that occurs at nongrammatic junctures (DeJoy and Gregory, 1985). 
CHAPTER II

\section{REVIEW OF THE LITERATURE}

This chapter reviews the 1 iterature which pertained to (1) a rationale for examining 4-year-old children, (2) a rationale for examining normal disfluency rates and types, (3) what is thought to be known about normal disfluency rates and types (4) occurrence of normal disfluencies at the discrete age levels of 3-, 4-, and 5-years-of-age, (5) characteristics of incipient stutterers (for comparison to normal speakers), (6) high risk-low risk fluency types (for comparison to normal speakers), and (7) theories of disfluency that relate specifically to a cultural or racial group of people.

RATIONALE FOR EXAMINING NORMAL DISFLUENCIES IN FOUR-YEAR-OLD CHILDREN

The age range of greatest interest among investigators of normal and abnormal disfluencies was between 2- and 6-yearsof-age (Young, 1975; DeJoy and Gregory, 1985). There are two reasons why investigators are interested in this age range: (1) the onset of stuttering is most frequent1y observed during this time (Johnson, 1959; Van Riper, 1971; DeJoy and Gregory, 1985), and (2) normal children are particularly disfluent during these ages (Muma, 1971). 
For this study the age of 4 was decided upon for the following reasons: (1) this age was in the middle of the range in which children are particularly disfluent, (2) 4 -year-old children were generally prone to produce more and longer utterances than 2-and 3-year-olds, and (3) 4-year-old children were more intelligible than 2-or 3-year-olds.

RATIONALE FOR EXAMINING NORMAL DISFLUENCY RATES

According to Shapiro and DeCicco (1982) there are two views prevalent in the literature concerning the disfluencies found in stuttering and nonstuttering children. First, that there are no qualitative and/or quantitative differences between normally disfluent children and incipient stutterers. Wendell Johnson's Diagnosogenic Theory advances this view. Johnson (1942) proposed that there were no qualitative or quantitative differences between stuttering at its onset and the speech of normal children, and that the difference came from how they were evaluated by others (Meyers, 1968). After 45 years the influence of the Diagnosogenic Theory is still with us (Meyers, 1986).

A second view of the relationship between stuttering and normal disfluencies, as stated by Shapiro and DeCicco (1982) was that they were not related and stuttering was distinctly different from the disfluencies of nonstutterers. McDearmon (1968) reanalyzed Johnson's data and found qualitative differences between the two groups in the form of partword repetitions. Boehmler (1958), Sanders (1963), Floyd 
and Perkins (1974), Adams (1977), Panelli, McFarlane, and Shipley (1978), Bjerkan (1980), Shapiro and DeCicco (1982), Culp (1984), Yairi and Lewis (1984), Young (1984), Meyers (1986), and Pindzola and White (1986) have found qualitative and quantitative differences between children with fluency disorders and normally disfluent children.

The high variability of disfluencies in children makes differential diagnosis difficult, but differential diagnosis is feasible if young stutterers differ quantitatively and qualitatively from normally speaking children (Meyers, 1986). This would avoid a delay in identification and treatment. Panelli et al. (1978), Riley and Riley (1979), and Adams (1980) suggest that children who were seen earlier and within the first year of onset had the best prognosis for recovery. The reversal of stuttering in preschool children has been reported by several clinics (Riley and Riley, 1979; Culp, $1984)$.

Better understanding of the normal speech of children will help us to gather normative data on childhood disfluencies and better identify atypical speech in children (Metraux, 1950; DeJoy and Gregory, 1985; Meyers, 1986).

Researchers have used three methods to collect data to support the view that there are qualitative and quantitative differences between stutterers and nonstutterers: (1) comparisons of the disfluencies of stutterers, (2) identification of stutterers versus nonstutterers by listening to their speech, and (3) analysis of the disfluencies of nonstutterers 
(Shapiro and DeCicco, 1982). This study employed the third method.

\section{NORMAL FLUENCY RATES AND TYPES}

Johnson's Diagnosogenic Theory placed importance on normal disfluency in the thinking and research on stuttering (Bloodstein, 1981). Disfluency is not the same thing as stuttering. The majority of people are disfluent at one time or another but only a few become stutterers.

\section{Frequency}

The mean total of disfluencies per 100 words spoken by normally disfluent children was reported to be between 5 or 6 (Adams, 1977), and 7.65 (Yairi and C1ifton, 1972). The disfluency of normally speaking children tended to decrease with age (Davis, 1939; Branscom et al., 1955; Bloodstein, 1981).

Wexler and Mysak (1982) stated that a maximum of 3 units per instance of repetition had been found in nonstutterers. They stated further that occasional multiple repetitions in the speech of 2-, 4-, and 6-year old males, should not be considered evidence of early stuttering. In contrast to this, Yairi and Lewis (1984) found the instances of more than 2 repetitions, in both male and female 2- and 3-year-old children, extremely rare. 
Types

Repetition, which varies greatly in type and frequency between children, is produced in the speech of all children (Davis, 1939). A ratio between syllable, word, and phrase was computed by Wingate (1962a) from Branscom et a1. (1955) in which data were compiled from five studies done by Davis in 1939, Branscom in 1942, Hughes in 1943, Oxtoby in 1943, and Johnson in 1945 . The ratio between these repetition types was found to be $1: 2: 3$. In other words, syllable repetition was half as frequent as word repetition and only a third as frequent as phrase repetition. Word repetition correlated to some extent with syllable and phrase repetition but no significant correlation existed between syllable repetition and phrase repetition (Wingate, 1962a).

Word Repetition. One of the nonfluency types that tends to be in the speech of nonstuttering children is word repetition (Andrews et a1., 1983; Davis, 1939; DeJoy and Gregory, 1985). Meyers (1986) stated that in her study normally disfluent children had significantly more whole word repetitions than did stutterers. Bjerkan (1980) found great variety in frequency of occurrence between subjects. Most of the children had a frequency below average and $65 \%$ of the children repeated less than $6 \%$ of the words. It was reported that these whole word repetitions consist of 1-2 units of the word being repeated (Bloodstein, 1981). Whole word repetitions have been judged as a nonstuttering type of disfluency 
(Hedgeman and Hartman, 1979), and tend to decrease over age (Davis, 1939; Wingate, 1962a; Bjerkan, 1980).

Phrase Repetition. Phrase repetition was another type of disfluency which marked the speech of nonstuttering preschool children (Johnson, 1955; Davis, 1939; DeJoy and Gregory, 1985). As with word repetition, phrase repetition had been judged a nonstuttering disfluency type (Hedgeman and Hartman, 1979). Also, as with word repetition, phrase repetition decreased with age (Wingate, 1962a; Davis, 1939). Interjection. Interjection was a third disfluency type which was commonly found in preschool children. According to the literature it evidences higher frequencies, along with revision and incomplete phrase, in the speech of nonstutterers than any of the remaining categories (DeJoy and Gregory, 1985; Haynes and Hood, 1977; Yairi, 1981; Wexler and Mysak, 1982). Yairi and Lewis (1984) found it to be the most frequent disfluency type, and interjection, along with revision, was most likely to be evaluated as normal disfluency (Boehmler, 1958; Hedgeman and Hartman, 1979).

Revision-Incomplete Phrase. A fourth type of disfluency that tended to be in the speech of preschool children was revision-incomplete phrase (Johnson, 1955; DeJoy and Gregory, 1985; Andrews et a1., 1983). This type of disfluency (along with interjection) evidenced higher frequencies than the other types (Haynes and Hood, 1977; Yairi, 1981; Wexler and Mysak, 1982), appeared significantly more in the speech of 
children with normal disfluencies than in the speech of stutterers (Meyers, 1986), and was more likely to be evaluated as a normal disfluency (Boehmler, 1958; Huffman and Perkins, 1974). In contrast, Yairi and Lewis (1984) found it to maintain third position behind interjection and partword repetition in 2- and 3-year-old children.

In conclusion, according to the literature word repetition, revision-incomplete phrase, interjection, and phrase repetition appear to be the disfluency types most associated with normal disfluency. When attempting to develop or interpret normative fluency data, researchers and clinicians should be aware of changes in the frequency of specific disfluency subtypes as children grow older (Haynes and Hood, 1977).

NORMAL DISFLUENCY RATES AND TYPES AT DISCRETE AGE LEVELS

\section{Three-Year-01ds}

Most 3-year-olds produce easy, effortless repetitions (Metraux, 1950) and appear to be more disfluent than 5-yearolds (DeJoy and Gregory, 1985), but less disfluent than 2-year-o1ds (Branscom et a1., 1955; Davis, 1939). Threeyear-olds produce all types of disfluencies (DeJoy and Gregory, 1985). Branscom et al. (1955) reported that in both the Oxtoby 1943 and Davis 1939 study, part-word 
repetition, including syllable repetition, appears less frequently than do phrase and word repetition. Revision (Yairi and Lewis, 1984; DeJoy and Gregory, 1985) and interjection (Metraux, 1950; Yairi and Lewis, 1984; DeJoy and Gregory, 1985) appear more frequently than disrhythmic phonation (Metraux, 1950; DeJoy and Gregory, 1985) or intrusive schwa (Metraux, 1950; Curlee, 1980).

Four-Year-01ds

Early studies conducted by Davis (1939) and Metraux (1950) found that children produced fewer repetitions at 4-years-of-age when compared to younger children. Davis studied 274.2 - to 5.0-year-olds and again found phrase repetition to be the most frequent disfluency type followed by word repetition with syllable repetition being the least frequent.

In 1943 Hughes conducted a study involving 29 4-yearold children (Wingate, 1962a). It was found that word repetition occurred most frequently in the speech of these children with part-word repetition the next most frequently occurring followed by phrase repetition (Wingate, 1962a).

Branscom et al. (1955) reported on the repetitions of 42 4-year-olds in the combined studies of Hughes, Branscom, and Johnson. Interestingly, word repetition was the most frequently occurring disfluency type followed by syllable repetition with phrase repetition being the least frequent, and less frequent than in the 2-, 3-, and 5-year-olds. The 
total frequency count of repetition disfluencies was less than for the 3-year-olds.

A more recent study conducted by Haynes and Hood (1977) enlisted 30 subjects, 10 from each of the ages of 4,6 , and 8 . In this study, as in DeJoy and Gregory (1985), revisionincomplete phrase was divided into two separate categories. The disfluencies in the 104 -year-old subjects occurred in the following order from most to least frequent: revision, word repetition, phrase repetition, interjection, part-word repetition, dischythmic phonation, and incomplete phrase. There were no occurrences of tense pause. Part-word repetition occurred significantly less than revision, word repetition, phrase repetition, and interjection. Haynes and Hood's study found that total disfluency was approximately the same for the 4-year-olds as for the 6- and 8-year-olds in their study. The disfluency types which were observed changed slightly at each age level.

In 1982 Wexler and Mysak studied 12 4-year-old male children and found similar frequencies for part-word repetition, phrase repetition, and revision-incomplete phrase in 4-year-olds as in Haynes and Hood's 1977 study (DeJoy and Gregory, 1985). There is general agreement among investigators of normal disfluencies as to the rank order of fluency types by frequency of occurrence. An exception is the study by Wexler and Mysak (1982) where the rank order of fluency types by frequency of occurrence was as follows: interjection, revision-incomplete phrase, tense pause, word repetition, 
disrhythmic phonation, phrase repetition, and the least occurring, part-word repetition. As in other studies, the two most frequently occurring disfluency types were revisionincomplete phrase and interjection. The 4-year-olds were similar to the 6-year-olds in frequency of disfluency types. In Wexler and Mysak's study, between the ages of 2 and 4 there was a statistically significant decline in word and phrase repetition, and nonsignificant reductions in revisionincomplete phrases and total disfluencies (DeJoy and Gregory, 1985) .

Five-Year-01ds

Five-year-olds produce all disfluency types. Branscom et al. (1955) and DeJoy and Gregory (1985) reported a reduction in the number of total disfluencies in 5-year-olds when compared to younger children. DeJoy and Gregory (1985) reported that certain types of disfluencies decreased substantially from the 3-1/2-year-olds while others declined only slightly. The disfluencies commonly associated with young children's speech such as repetition, incomplete phrase, and disrhythmic phonation were those which declined significantly, while interjection and ungrammatical pause did not decline significantly, and grammatical pause was significantly more frequent in the 5-year-old subjects. DeJoy and Gregory also noted that the frequency of many disfluencies from the 5-year-old subjects in their study fell midway between the 4- and 6-year-olds in the Haynes and Hood 1977 study. 
Five-year-olds produce more revision, interjection, and word repetition than part-word repetition or tense pause (Branscom et a1., 1955; DeJoy and Gregory, 1985; Yairi and Clifton, 1972).

\section{INCIPIENT STUTTERING CHARACTERISTICS}

Frequency and type of disfluencies are important in judgments of fluency, disfluency, and stuttering and are associated with incipient stuttering (Hedgeman and Hartman, $1979)$.

\section{Frequency}

Adams (1977), Gregory and Hill (1980), and Shapiro and DeCicco (1982) stated that the stutterers in their studies showed a high frequency of all disfluency types and Meyers (1986) stated that children with a great number of more unusual disfluencies showed an increased occurrence of all disfluency types. As the frequency of disfluency increased, the number of stuttering judgments increased (Boehmler, 1958; Curran and Hood, 1977; Hedgeman and Hartman, 1979; Huffman and Perkins, 1974; Sanders, 1963). There has been some controversy over how much more a stutterer stutters. In 1977 Adams found stutterers to be twice as nonfluent when compared to nonstutterers, and Yairi and Lewis (1984) reported that stutterers were three times as disfluent as nonstutterers in their study. The total nonfluencies of a stutterer average 10 or more per 100 words spoken (Adams, 1977) and Yairi and Lewis report that the total nonfluencies of stutterers 
in their study averaged 21.5 disfluencies per 100 syllables (not words). Degree of variability in disfluency rate has been cited as a distinguishing characteristic of the early phases in the development of stuttering in young children (Meyers, 1986).

Number of repetition units influence judgments of stuttering when they comprise $10-15 \%$ of the speech sample (Hedgeman and Hartman, 1979). Sanders (1963) reported that speech was judged as stuttering when single-unit repetitions occurred 8 times per 100 words spoken. In contrast, Huffman and Perkins (1974) found that listeners judged a speaker as a stutterer when a single-unit repetition occurred once in 50 words. Double-unit repetitions ("ba-ba-ball") evoke judgments of stuttering more often than single-unit repetitions when the number of disfluencies was held constant (Hedgeman and Hartman, 1979; Sanders, 1963). According to Andrews et al. (1983), one thing which identified speech as stuttered was double-unit repetition.

\section{Types}

Young (1984) stated that type of disfluency is probably the major factor in judging speech behavior as stuttered and that the increase in disfluencies in incipient stutterers was not uniform across all disfluency types. Johnson (1959) found that the stutterers in their study exceeded the nonstutterers in most disfluency types except interjection, revision and incomplete phrase. Young found the increase most significant for part-word and disrhythmic phonation with 
the largest difference occurring on part-word repetition when seen near the time of the intitial diagnosis.

Repetition is a type of disfluency and a major characteristic of incipient stutterers. Huffman and Perkins (1974) reported that repetitions generated more stutterer responses than prolongations and hesitation, and Bloodstein (1960b) stated that repetition was the dominant feature of stuttering and most frequently was reported by parents as the earliest noticed symptom of the disorder.

Part-Word Repetition. Bloodstein $(1960 \mathrm{~b})$ reported that in the early stages of stuttering, between 2 and 6 or 7 , repetitions tended to have certain characteristics which were not found later. These characteristics were: (1) deliberate and effortless repetitions, and (2) frequent repetition of single syllable words, in addition to sound repetitions, which would later dominate the repetitions. This was similar to Van Riper's (1963) primary stuttering.

Part-word repetition, comprised of sound and syllable repetition, appeared frequently in the literature as a type of disfluency characteristic of incipient stuttering. Meyers (1986) stated that the most common disfluency for young stutterers was part-word repetition and according to Shapiro and DeCicco (1982) stutterers showed a higher percentage of part-word repetition than other disfluency types. Part-word repetition comprised part of the first "kernel" characteristic of stuttering for Wingate in 1964 and Wexler 
and Mysak (1982) found that part-word repetition was one of the two disfluency characteristics which differed significantly between stutterers and nonstutterers. According to Young (1975) stutterers evidenced more than four times as many overall part-word repetitions than nonstutterers and a possible relationship between rated severity of stuttering and frequency of part-word repetition had been noted by Boehmler (1958) and Young (1975).

In part-word repetitions stutterers exceeded nonstutterers in the number of times a segment of speech is repeated. In a study by Yairi and Lewis (1984) it was found that the stutterers repeated a segment of speech an average of 1.72 times and many stutterers frequently repeat partword repetitions twice or more per instance of repetition. Adams (1977) found that one characteristic of an incipient stutterer is the occurrence of at least 3 repetitions of the unit being repeated. According to Yairi and Lewis, 3 units may be too stringent a criterion.

Syllable repetition, part of the definition of partword repetition, is specifically mentioned in the literature. Syllable repetition, according to Davis (1939), is one of the best measures for determining those children who deviate markedly from the normally disfluent child, and are the units of speech on which disfluencies are most likely to be judged as stuttered (Johnson, 1959; Wingate, 1962b; Floyd and Perkins, 1974; Sanders, 1961). Early stuttering has been reported to consist of syllable repetitions which appear to 
occur most frequently on the initial word of the utterance (Johnson, 1959; Bloodstein, 1960a). The lowest percentage of syllable repetition found by Floyd and Perkins (1974) in stutterers was $7.28 \%$ and the mean percent of syllable disfluencies for stutterers was $9.88 \%$.

Disrhythmic Phonation. Disrhythmic phonation is a type of disfluency that does not involve repetition and is found frequently in the speech of incipient stutterers (Boehmler, 1958; Williams and Kent, 1958; Wingate, 1962b; Adams, 1977; Yairi and Lewis, 1984). Prolongation is included within the definition of disrhythmic phonation. According to wingate (1964), audible and silent prolongations are the second of two "kerne1" characteristics of stuttering and have been found to significantly differentiate stutterers from nonstutterers according to Wexler and Mysak (1984). Early diagnosed cases of stuttering involves the production of prolongations (Bloodstein, 1981). Curran and Hood (1977), Huffman and Perkins (1974), and Sanders (1961) maintain that the probability of speech being identified as stuttered depends, for one, on audible prolongations. In the Johnson, Brown, Curtis, Edney, and Keaster 1956 study (Adams, 1977) young stutterers evidence more than 10 times as many sound prolongations as nonstutterers. Prolongations are judged as stuttering if they exceed 1 second (912 milliseconds) in duration (Lingwall and Bergstrand, 1979). 
Tense Pause. Tense pause has also been identified in incipient stutterers (Young, 1961). Tense pause significantly occurs more frequently in the speech of stutterers than nonstutterers (Meyers, 1986). Interruptions in air flow or voice in young stutterers is reported by Adams (1977), and Johnson (1980). Interestingly, Huffman and Perkins (1974) found that tense pause did not prove to be a significant factor in identifying speech as stuttered or nonstuttered when it was presented separately.

Intrusive Schwa. Incipient stutterers have been noted to substitute the schwa for the vowel in the repeated unit (Van Riper, 1971; Adams, 1977; Curlee, 1980). Curlee (1980) maintained that substitution of the schwa for a vowel while accompanied by tension is an indication of an incipient stutterer.

Word Repetition. Word repetition is another type of repetitive disfluency found in some incipient stutterer's speech. Until word repetition is designated either monosyllabic or multisyllabic it will be difficult to assimilate and prioritize the available information. Increasing frequency of word repetitions increases judgments of stuttered speech (Hedgeman and Hartman, 1979). Whole word repetitions have been identified as the central feature of early stuttering by Bloodstein (1981) but had only secondary importance in the Yairi and Lewis (1984) study. 
In summary, frequency and type of disfluency are the major characteristics which separate stutterers from nonstutterers (Riley, 1972). Frequency can be broken down into overall frequency rates per 100 words and number of repetition units per segment being repeated. Overall frequency rates for stutterers appear to average 10 or more per 100 words spoken. Two or more repetitions of the unit being repeated appears to be a danger sign and evidence of incipient stuttering. Any form of disfluency, if it interrupts the flow of speech often enough or severely enough, is regarded as stuttering. According to the literature, the types of disfluency most identified with incipient stutterers can be summarized as (1) part-word repetition (Meyers, 1986; Shapiro and DeCicco, 1982; Wexler and Mysak, 1982; Wingate, 1964; Young, 1961), (2) disrhythmic phonation (Adams, 1977; Boehmler, 1958; Wingate, 1962a, 1964; Williams and Kent, 1958; Yairi and Lewis, 1984), (3) tense pause (Adams, 1977; Johnson, 1980; Meyers, 1986; Young, 1961), and (4) intrusive schwa (Adams, 1977; Curlee, 1980; Van Riper, 1971).

\section{HIGH RISK-LOW RISK FLUENCY TYPES}

According to Wexler (1982) adequate labeling of disfluencies as normal, disordered, or as a danger sign has been difficult. This is due to many factors, one of which 
is research designs (Wexler, 1982). Wexler states that past research has been fraught with problems such as: (1) not focusing on specific age levels, (2) using only one age level, (3) using questionable recording techniques, and (4) inadequate numbers of subjects for drawing valid conclusions. In addition, according to Wexler (1982), the descriptions of disfluent behavior vary from study to study. The lack of common terminology between investigators has a deleterious effect on the assimilation and understanding of this speech behavior.

Figure 1 shows high and low risk fluency types and frequency. The chart was compiled from the following 20 studies: Adams, 1977; Bloodstein, 1981; Bloodstein and Grossman, 1981; Curlee, 1980; Curran and Hood, 1977; Hedgeman and Hartman, 1979; Huffman and Perkins, 1974; Johnson, 1959, 1980; Lingwall and Bergstrand, 1979; Meyers, 1986; Perkins, 1971; Pindzola and White, 1986; Riley and Riley, 1979; Sanders, 1961; Shapiro and DeCicco, 1982; Van Riper, 1971; Wexler and Mysak, 1984; Wingate, 1962b; and Yairi and Lewis, 1984. 
Type

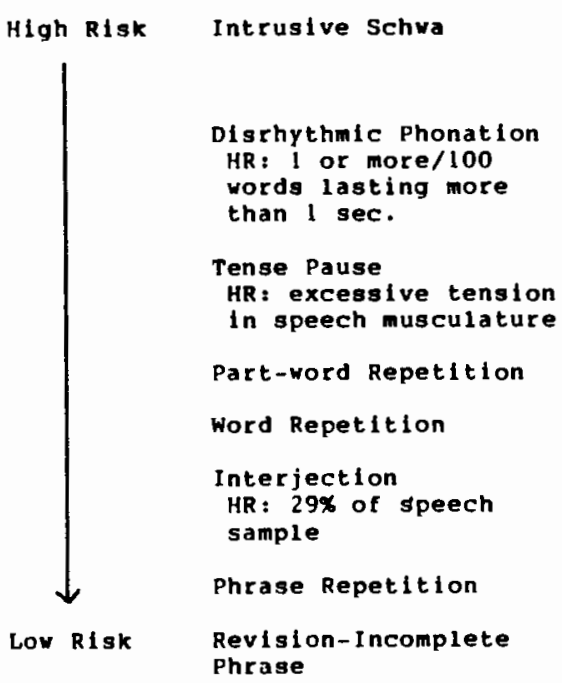

Frequency

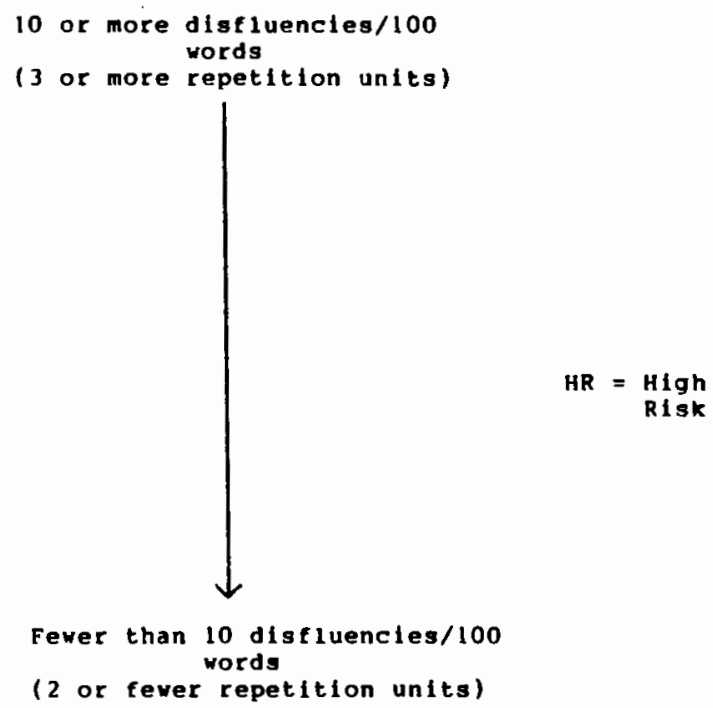

Figure 1. Type and frequency display for estimating abnormality of distiuency.

High risk disfluency types appear to encompass excessive interruptions in the flow of speech and are especially meaningful when they appear (1) within a word, (2) between words within a sentence, and/or (3) show evidence of physical and/or emotional stress. Please note that the top three risk types do not of themselves represent repetitions.

Any disfluency type when done to excess, drawing attention to itself and away from the message, is apt to be considered stuttering. 


\section{THEORIES OF DISFLUENCY WHICH RELATE SPECIFICALLY TO A CULTURAL AND RACIAL GROUP OF PEOPLE}

Stuttering appears to be found in almost all people and cultures throughout the world (Van Riper, 1971). We do not know what causes stuttering. It is such a complex disorder it appears that there may be many causes. There are many theories about the etiology of stuttering. Bloodstein (1981) organizes such theories by using the three major hypotheses about the moment of stuttering as a basis. The three theories are: (1) breakdown theories, (2) anticipatory struggle theories, and (3) repressed need theories. Breakdown theories point toward the effects of early environmental stress and also place genetics or "constitutional predisposing factors" in an important role in the development of stuttering (Bloodstein, 1987). Anticipatory struggle theories credit the disorder to parental attitudes toward disfluency and/or pressures for fluent speech. According to Bloodstein (1981) the last classification of the theories of stuttering is the repressed needs theories which deal with neurotic behavior and stuttering. Both breakdown theories and to a lesser degree, anticipatory struggle theories, directly relate to cultural and/or racial differences.

In 1911, when Francis Galton died, the eugenics movement which he had founded was flourishing (Freedman, 1983). During the 1920's the two positions, nature and nurture, contended for the prime position for the explanation of human variability. This struggle for top position made way for the 
doctrine of cultural determinism in which human behavior was explained in purely cultural terms (Freedman, 1983). The increase in controversy brought about Wendell Johnson's 1944 studies (Johnson, 1972) and Margaret Mead's Samoan research in which they suggested that there were groups of people who did not stutter. According to Bloodstein (1987) the claim that stuttering is absent from any society is a hypothesis that is very difficult to prove. On the other hand, the hypothesis that stuttering is found in every society of the world is equally as difficult to prove. It is more important to discover if there are any cultural differences in the incidence of this disorder and other verbal behaviors and what causes these cultural differences (Bloodstein, 1987; Fienup-Riordan, 1982).

There is evidence of various cultures which are found to have different amounts of stuttering (Leavitt, 1974; Bloodstein, 1987; Lemert, 1972). In 1959 Noroll stated that stuttering may be an index of cultural stress (Leith, 1986). There appears to be a correlation between the incidence of stuttering and cultures with high standards of conduct and achievement (Leith, 1986; Lemert, 1972). Cultures which have most or all of these characteristics are called "tough" societies (Leith, 1986). Cultures which have few of these characteristics are called "easy" societies and appear to have a lower incidence of stuttering. "Easy" societies have clear and open paths to social goals and 
generally have no word in their lexicons for stuttering (Leavitt, 1974; Leith, 1986).

According to Johnson (1980) parents are not usually the cause but part of the environment which maintains the disfluent speech patterns of the child. Johnson stated that disfluency judgments made by the parent about the child's speech are an important part of the child's semantic environment. As the child internalizes these judgments he begins to also evaluate his speech as disordered which may cause his speech to become more stuttered.

According to Gregory and Hill (1980) case studies have pointed out that subject variability, in addition to environmental or cultural factors, contributes to stuttering in children. This variability may be attributed to genetic differences. Bloodstein (1987) stated that many breakdown theories suggest that the child must be predisposed to the disorder before his/her speech would become stuttered under cultural stress and pressure. A majority of the theories identify this predisposition as genetic and submit that stuttering is a joint product of heredity and environment (Bloodstein, 1987; Kidd, 1983). The tendency for stuttering to run in families suggests a genetic basis for stuttering (Kidd, 1984; Bloodstein, 1987). It appears that extreme environmentalists were wrong not to recognize the part heredity plays in the modification of different types of people and behavior, and extreme hereditarians were wrong to ignore 
the influence of environment upon genetic predisposition (Kidd, 1984).

In conclusion, stuttering appears to be brought about by a combination of heredity (genetic transmission) and environment (culture). The extent to which each of these aspects plays a part in the development of stuttering is unknown and a point of controversy.

According to the literature normal 4-year-old children produce all disfluency types and appear to produce fewer repetitions than younger children. Word repetition, phrase repetition, interjection, and revision-incomplete phrase are considered low risk disfluencies and are usually found in the speech of normal children. Part-word repetition, disrhythmic phonation, tense pause, intrusive schwa, and sometimes word repetition are considered high risk disfluencies and are usually found in smaller quantities than the low risk disfluencies in the speech of normal children.

The mean total of disfluencies per 100 words spoken by normally disfluent children in the majority of studies reviewed range between 5 and 7.65 except for the Wexler and Mysak (1982) and Wexler (1982) studies which are unique in their reported high means of 9.10. This can be accounted for by the frequent identification of tense pause not noted by other researchers. Repetition instances in normally disfluent children are usually comprised of 2 or fewer units. The incipient stutterer averages 10 or more nonfluencies per 
100 words and repetition instances can be comprised of 3 or more units.

Stuttering appears to be found in almost all people and cultures throughout the world. Although the exact cause or causes of stuttering are unknown, it appears that stuttering may be brought about by a combination of heredity and environment. The Alaska Native children have had and stil1 partially have, a different genetic and cultural environment than the majority of Caucasian children in Alaska. It appears from the literature that these differences could have an effect on the frequency and type of disfluencies produced by both groups of children. 
METHODS

\section{SUBJECTS}

For the purposes of this study 17 normal Caucasian and 17 normal Alaska Native children between the ages of 42 to 54 months were selected from the Kenai Peninsula. There was no attempt to control socioeconomical level. The children in both groups met the following criteria:

1. no reported history of physical or developmental delay;

2. English (as normally spoken by the people in this region) being the primary language in the home;

3. passed a hearing screening test at $25 \mathrm{~dB} \mathrm{HL}$ for the pure tone frequencies of $500,1000,2000$, and $4000 \mathrm{~Hz}$;

4. mean length of response: $2-1 / 2$ words or longer;

5. speech intelligibility of at 1east $75 \%$ as determined by the examiner;

6. no reported prior identification or intervention for fluency problems;

7. able to attend to examiner for 15 minutes;

8. Alaska Native children must be at least $25 \%$ Alaska Native, as reported by native hospital and/or parent ; 
9. healthy at the time of the taping;

10. parental or caregiver's permission to be in the study .

\section{SUBJECT SELECTION PROCEDURES}

The examiner contacted preschools and the native hospitals in the area and requested a 1 ist of parents or caregivers with 4-year-old Caucasian and/or Alaska Native children.

A letter of introduction stating the intent of the study was mailed or delivered to the prospective parents or caregiver (see Appendix A). A self-addressed stamped envelope was provided in which the parent or caregiver returned a form stating interest in participating in the study (see Appendix $B)$. Upon receiving the form stating interest, the examiner called and set up an appointment with the parent or caregiver. During this meeting the parent or caregiver was asked to fill out a demographic questionnaire which addressed the medical, developmental, speech, and familial history, and to sign a consent statement (see Appendix C). At this time a 3 -minute speech sample was elicited from the subjects and recorded on a portable tape recorder to evaluate speech intelligibility and language development. The speech sample was elicited by means of open-ended questions and toys (see Appendix D). The total number of words were counted and divided by the number of responses to determine the subject's mean length of response. If 75 out of 100 consecutive 
words were understood the subject was judged to be at least 75\% intelligible. In addition, the subject was given a pure tone hearing screening test at $25 \mathrm{~dB}$ at 500, 1000, 2000, and $4000 \mathrm{~Hz}$.

\section{SPEECH SAMPLE PROCEDURES}

Each subject was videotaped in a separate 15-minute session (range 7 to 60 minutes) consisting of free play and conversation with the examiner. The interaction and conversation between the subjects and the investigator was videotaped by a Zenith VC 1000 system. The investigator used free play, open-ended questions, and parallel talk while playing with the toys to elicit spontaneous speech from the subject. If after 8 minutes the child was not verbalizing the investigator returned the toys to the box and asked the subject open-ended questions for the remaining 7 minutes.

The interaction between the investigator and child was videotaped by a stationary video camera on wide angle lens. The videotaping took place in the same room in which the investigator and subject were interacting.

\section{SCORING PROCEDURES}

The subject's 300-word language sample was transcribed verbatim from the audio and video recordings by the investigator. After transcription the investigator identified and classified specific disfluencies (see Appendix E for rules for calculating word samples). The disfluencies were 
classified as follows: part-word repetition, word repetition, phrase repetition, interjection, revision-incomplete phrase, disrhythmic phonation, tense pause, and intrusive schwa. The rules used to identify and classify the disfluencies were taken from Branscom et al. (1955) and modified by graduate students of the Portland State University Speech and Hearing Program (see Appendix F and Appendix G).

\section{RELIABILITY}

The reliability of the investigator's identification and tabulation of disfluencies was assessed as follows: 5 samples were randomly selected, through the use of random order tables, from the videotaped recordings. Content transcriptions were formulated for 10 utterances of not less than 30 words from each of the 5 transcripts by a second year graduate student in the Portland State Speech and Hearing Science Program (see Appendix H). The content transcripts provided the basic information given in the subject's utterance but deleted any type of disfluency. Two judges and the investigator then viewed the video selections, identifying and coding any disfluencies. The results of the judges were compared to the investigator's results.

A self-agreement index (Sanders, 1961) was calculated to determine intrajudge reliability. The intrajudge reliability was $100 \%$. 
Interjudge reliability was calculated by dividing the number of utterances agreed upon by the judges by the total number of utterances. The interjudge reliability was $97 \%$.

\section{DATA ANALYSIS}

The eight types of disfluencies were identified and tabulated, the mean and standard deviation of the percentage of disfluencies was calculated for each type of disfluency as well as for the total disfluencies per 300 words. The analysis of variance was used to evaluate any statistically significant differences between all types and total amounts of disfluencies in the two research groups. All F-values were compared at the 0.05 level of probability. 


\author{
CHAPTER IV \\ RESULTS AND DISCUSSION
}

\title{
RESULTS
}

The purpose of this study was to compare the frequency of specific disfluencies in 4-year-old Alaska Native children and 4-year-old Caucasian children, in terms of part-word repetition, word repetition, phrase repetition, interjection, revision-incomplete phrase, disrhythmic phonation, tense pause, and intrusive schwa. Spontaneous speech samples were used to obtain the data on the disfluencies from 34 children; 17 Caucasian and 17 Alaska Native. The results will be used to answer the questions posed by this study:

1. Do 4-year-old Alaska Native children exhibit a higher frequency of disfluencies than 4-year-old Caucasian children?

The analysis of variance was used to analyze the data pertaining to the overall frequency of disfluencies for the two groups. This parametric test was chosen because the number of variables to be analyzed were multivariate and the populations were assumed to be normally distributed. After analysis of the data, a F-value of 0.06 was revealed indicating that a statistically significant difference was not apparent at the .05 level of probability (Table I). 
TABLE I

SUMMARY OF THE ANALYSIS OF VARIANCE F-TEST FOR THE EFFECT OF RACE ON THE DISFLUENCIES PER 300 WORDS OF EIGHT INDIVIDUAL TYPES OF DISFLUENCY AND THEIR TOTAL

Disf luency

Type
F-Value
Significance at the .05 Level of Probability

Revision-Incomplete

Phrase

2.75

NS

Interjection

2.37

NS

Phrase Repetition

0.01

NS

Word Repetition

0.01

NS

Part-word Repetition

0.63

NS

Tense Pause

0.00

NS

Disrhythmic Phonation

1.80

NS

Intrusive Schwa

2.13

NS

Total Disfluency

0.06

NS

2. Do 4-year-old Alaska Native children exhibit a greater frequency of specific disfluencies, in terms of part-word repetition, word repetition, phrase repetition, interjection, revision-incomplete phrase, disrhythmic phonation, tense pause, or intrusive schwa than 4-year-old Caucasian children? Again, the analysis of variance, chosen for the reasons previously stated, was used to analyze the data pertaining to 
frequency of occurrence of specific disfluency types. An F-value was calculated of 2.75 for revision-incomplete prirase, 2.37 for interjection, 2.13 for intrusive schwa, and 1.80 for disrhythmic phonation. Also, there were F-values of 0.63 for part-word repetition, 0.01 for word repetition, 0.01 for phrase repetition, and 0.00 for tense pause. All of the above F-values were not significant at the .05 level of confidence (Table I).

3. Do 4-year-old Alaska Native and Caucasian children exhibit a higher frequency of low risk disfluency types (word repetition, phrase repetition, interjection, and revision-incomplete phrase) when compared to high risk disfluency types (part-word repetition, disrhythmic phonation, tense pause, and intrusive schwa)?

Two relative frequency histograms for the high and low risk disfluency types exhibited first by the Alaska Native children and second by the Caucasian children are presented in Figure's 2 and 3 .

Although the above three questions clearly indicate no mean differences between the control and experimental groups, there were interesting distributional differences when analyzed simply by means of descriptive statistics. 

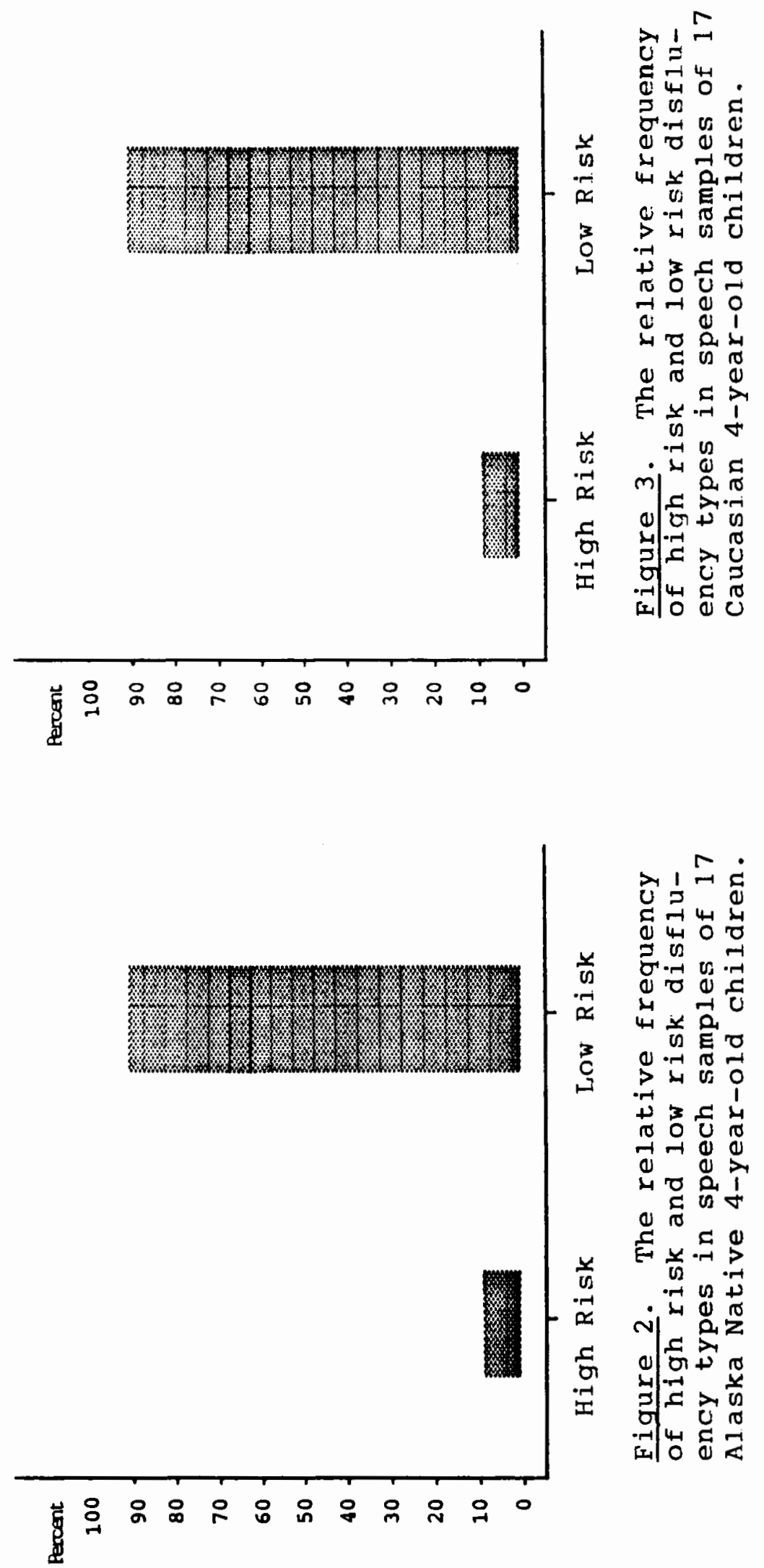


\section{Descriptive Statistics}

Since $F$-tests and t's address themselves to means rather than distribution within samples, visual inspection of the data indicated distribution variables within the two samples. When the Alaska Native children and the Caucasian children were placed in rank order from most frequent to least frequent disfluent subjects, divided into quartiles, and the means of these quartiles compared, it was found that the Alaska Native children produced lower rates of disfluency in the first three quartiles than the controls (see Table II, p. 41, and Figure 4, p. 42). Although the Alaska Native childrens' overall frequency of disfluency was similar to the Caucasian frequency of disfluency, the Caucasian children in each of the first three quartiles were more disfluent than the Alaska Native children. In the fourth quartile there was a dramatic reversal (see Table III, p. 43, and Figure 3, p. 39$)$.

Further, when both groups, Alaska Native and Caucasian, were collapsed into 34 subjects, placed in rank order and divided at the median, the Alaska Native children represented only 6 of the 17 children in the upper half and 11 of the 17 children in the lower half (see Table IV, p. 44, and Figure 5, p. 45). 
TABLE II

TOTAL HIGH RISK DISFLUENCIES OF ALASKA NATIVE

4--YEAR-OLD CHILDREN PER 100 WORDS SPOKEN

DIVIDED INTO QUARTILES

\begin{tabular}{|c|c|c|c|c|}
\hline Subj. & $\begin{array}{l}\text { Total Fre- } \\
\text { quency of } \\
\text { Disfluencies }\end{array}$ & $\begin{array}{c}\text { Types of HR } \\
\text { Disfluency Pro- } \\
\text { duced in Rank } \\
\text { order }\end{array}$ & $\begin{array}{l}\text { Total Dis- } \\
\text { fluencies } \\
\text { of Group }\end{array}$ & $\begin{array}{l}\overline{\mathrm{x}} \text { of } \\
\text { Group }\end{array}$ \\
\hline & & $Q_{4}$ & & \\
\hline 1 & 14.00 & $W R *$, DP, PWR & \multirow{4}{*}{43.35} & \multirow{4}{*}{10.84} \\
\hline 2 & 10.03 & WR, PWR & & \\
\hline 3 & 9.66 & WR, DP, PWR & & \\
\hline 4 & 9.66 & WR, PWR & & \\
\hline \multicolumn{5}{|c|}{$Q_{3}$} \\
\hline 5 & 7.66 & WR, PWR & \multirow{4}{*}{23.65} & \multirow{4}{*}{5.91} \\
\hline 6 & 6.00 & WR, PWR & & \\
\hline 7 & 5.33 & WR, PWR & & \\
\hline 8 & 4.66 & DP, WR & & \\
\hline \multicolumn{5}{|c|}{$\mathrm{\ell}_{2}$} \\
\hline 9 & 4.33 & & \multirow{4}{*}{13.66} & \multirow{4}{*}{3.42} \\
\hline 10 & 3.33 & WR & & \\
\hline 11 & 3.00 & WR & & \\
\hline 12 & 3.00 & & & \\
\hline \multicolumn{5}{|c|}{$\mathrm{Q}_{1}$} \\
\hline 13 & 2.33 & WR, PWR & & \\
\hline 14 & 2.00 & WR & & \\
\hline 15 & 1.66 & WR & 10.31 & 2.06 \\
\hline 16 & 1.33 & WR & & \\
\hline 17 & 1.33 & WR & & \\
\hline
\end{tabular}

PWR $=$ part-word repetition $\quad$ DP $=$ disrhythmic

WR $=$ word repetition phonation

*word repetition is a type of disfluency associated with the normally disfluent, highly disfluent, and stutterers depending upon its frequency ( $O$. Bloodstein, A Handbook on Stuttering, 4th ed. (Champaign-Urbana: University of Illinois Press, 1987). 


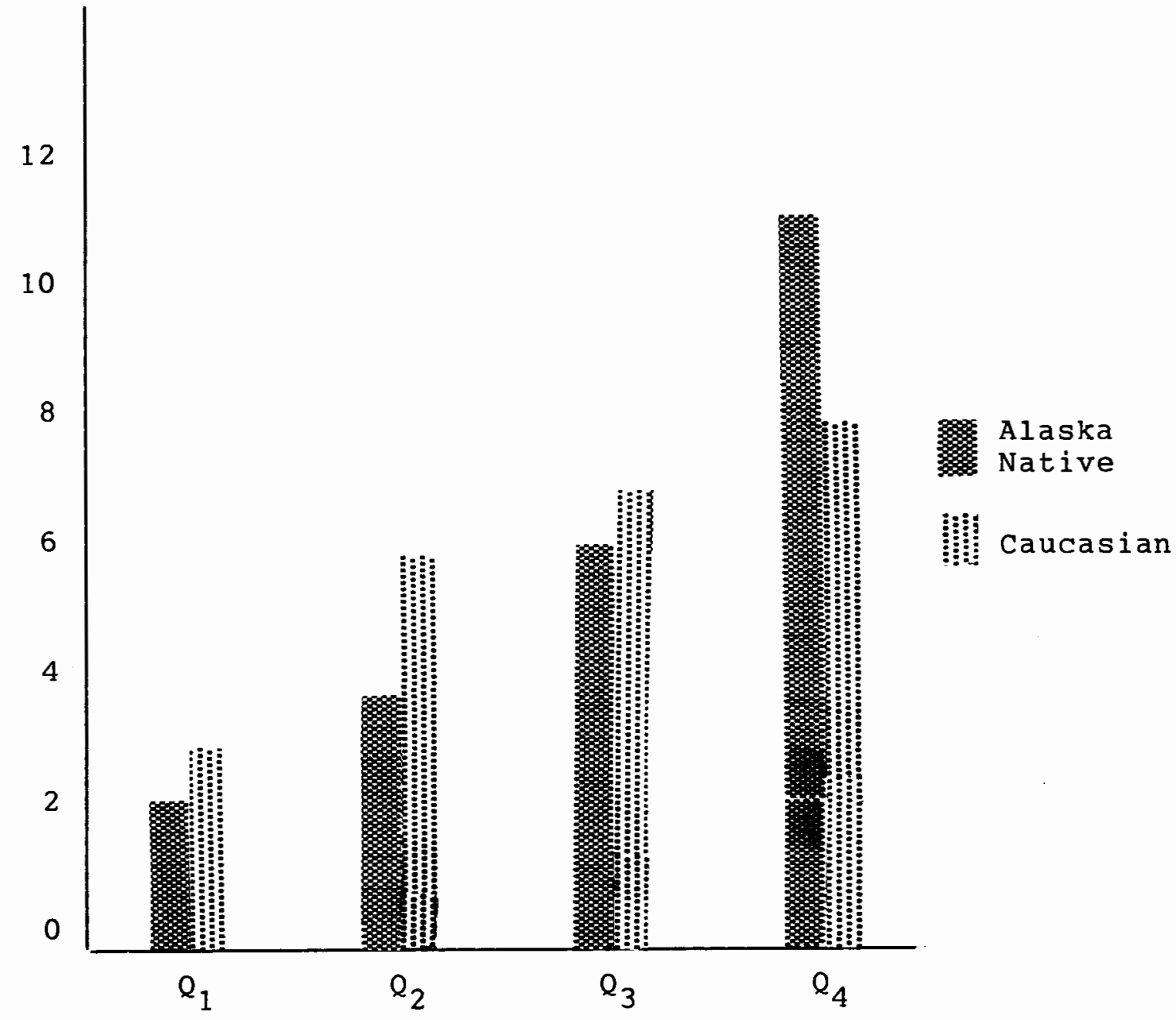

Figure 4. Mean frequency of disfluency per quartile for Alaska Native and Caucasian 4year-old children. 
TABLE III

TOTAL HIGH RISK DISELUENCIES OF CAUCASIAN 4-YEAR-OLD CHILDREN PER 100 WORDS SPOKEN DIVIDED INTO QUARTILES

\begin{tabular}{|c|c|c|c|c|}
\hline Subj. & $\begin{array}{c}\text { Total Fre- } \\
\text { quency of } \\
\text { Disfluencies }\end{array}$ & $\begin{array}{l}\text { Types of HR } \\
\text { Disfluency Pro- } \\
\text { duced in Rank } \\
\text { Order }\end{array}$ & $\begin{array}{l}\text { Total Dis- } \\
\text { fluencies } \\
\text { of Group }\end{array}$ & $\begin{array}{c}\bar{x} \text { of } \\
\text { Group }\end{array}$ \\
\hline & & $Q_{4}$ & & \\
\hline 1 & 8.66 & PWR, DP, TP & \multirow{4}{*}{$31 \cdot 32$} & \multirow{4}{*}{7.83} \\
\hline 2 & 8.66 & WR * & & \\
\hline 3 & 7.00 & WR, PWR & & \\
\hline 4 & 7.00 & WR, PWR & & \\
\hline \multicolumn{5}{|c|}{$Q_{3}$} \\
\hline 5 & 7.00 & WR, PWR & \multirow{4}{*}{25.99} & \multirow{4}{*}{6.50} \\
\hline 6 & 6.66 & WR & & \\
\hline 7 & 6.33 & WR & & \\
\hline 8 & 6.00 & WR, DP & & \\
\hline \multicolumn{5}{|c|}{$\mathrm{Q}_{2}$} \\
\hline 9 & 6.00 & WR, PWR & \multirow{4}{*}{22.99} & \multirow{4}{*}{5.75} \\
\hline 10 & 6.00 & PWR, WR & & \\
\hline 11 & 5.66 & WR, PWR & & \\
\hline 12 & 5.33 & WR， PWR & & \\
\hline \multicolumn{5}{|c|}{$Q_{1}$} \\
\hline 13 & 5.33 & WR, PWR & & \\
\hline 14 & 4.00 & WR, PWR & & \\
\hline 15 & 2.33 & WR, PWR & 13.66 & 2.73 \\
\hline 16 & 2.00 & PWR， WR & & \\
\hline 17 & 0.00 & & & \\
\hline
\end{tabular}

PWR = part-word repetition $W R=$ word repetition
$\mathrm{DP}=$ disrhythmic phonation

* Word repetition is a type of disfluency associated with the normally disfluent, highly disfluent, and stutterers depending upon its frequency (0. Bloodstein, A Handbook on Stuttering, 4th ed. (Champaign-Urbana: University of Illinois Press, 1987). 
A SPLIT ONE-HALF COMPARISON, COLLAPSING ALASKA NATIVE (AN)

AND CAUCASIAN (C) 4-YEAR-OLD CHILDREN BY RANK ORDER OF DISFLUENCY

\begin{tabular}{|c|c|c|c|}
\hline 14.00 & $(\mathrm{AN})$ & 5.33 & $(\mathrm{AN})$ \\
\hline 10.03 & $(\mathrm{AN})$ & 5.33 & $(\mathrm{AN})$ \\
\hline 9.66 & $(\mathrm{AN})$ & 5.33 & (C) \\
\hline 9.66 & $(\mathrm{AN})$ & 4.66 & $(\mathrm{AN})$ \\
\hline 8.66 & (c) & 4.33 & $(\mathrm{AN})$ \\
\hline 8.66 & (C) & 4.00 & (c) \\
\hline 7.66 & $(\mathrm{AN})$ & 3.33 & $(\mathrm{AN})$ \\
\hline 7.00 & (c) & 3.00 & $(\mathrm{AN})$ \\
\hline 7.00 & (c) & 3.00 & $(\mathrm{AN})$ \\
\hline 7.00 & (C) & 2.33 & (C) \\
\hline 6.66 & (c) & 2.33 & $(\mathrm{AN})$ \\
\hline 6.33 & (c) & 2.00 & (C) \\
\hline 6.00 & (C) & 2.00 & (AN) \\
\hline 6.00 & (C) & 1.66 & $(\mathrm{AN})$ \\
\hline 6.00 & (c) & 1.33 & $(\mathrm{AN})$ \\
\hline 6.00 & $(\mathrm{AN})$ & 1.33 & ( AN) \\
\hline 5.66 & (C) & 0.00 & (c) \\
\hline
\end{tabular}




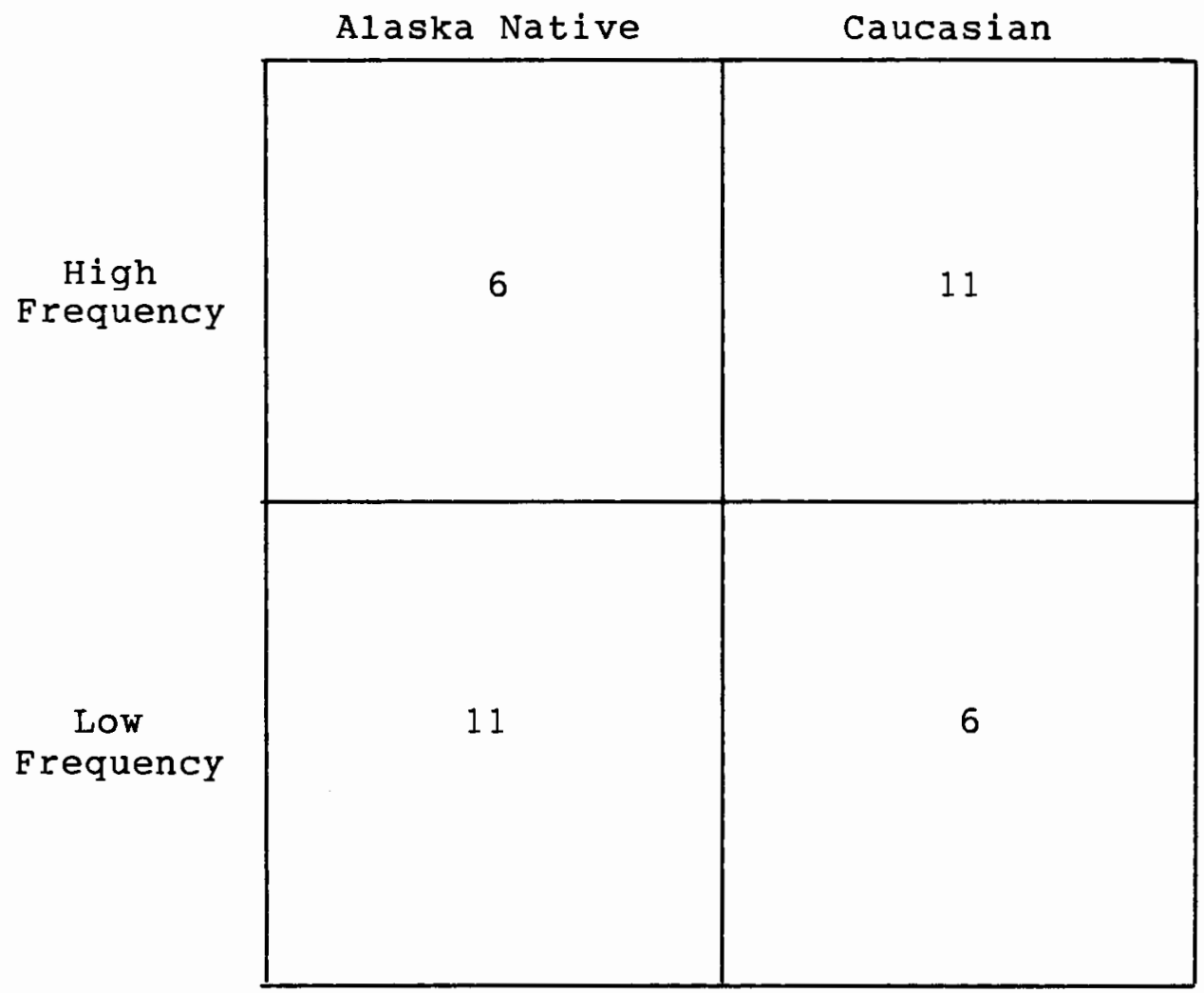

Figure 5. Number of Alaska Native and Caucasian children found in high frequency and low frequency categories, when divided at the median. 


\section{DISCUSSION}

Normal data on normal disfluency in the native population of Alaska is apparently nonexistent and without normative data it is difficult to differentiate disorder from normal ethnic variability. Descriptive, normative fluency data is needed and would help speech-language pathologists in differentiating developmental disfluency from incipient stuttering in Alaska Native children.

The first question posed by the present study was: Do 4-year-old Alaska Native children exhibit a higher frequency of disfluencies than 4-year-old Caucasian children?

Table $V$ presents the mean $(\bar{x})$ and standard deviation (S.D.) for both groups. The 4-year-old Caucasian children exhibited a mean of 5.53 disfluencies per 100 words and the 4-year-old Alaska Native children showed a mean of 5.27 disfluencies per 100 words. The Caucasian children demonstrated more of a consistency of disfluencies as reflected by a standard deviation of 2.23 whereas the 4-year-old Alaska Native children exhibited greater variability as evidenced by a standard deviation of 3.27 . 


\section{TABLE V}

RANK ORDER, TOTAL, MEANS, AND STANDARD DEVIATIONS FOR SEVEN INDIVIDUAL TYPES OF DISFLUENCIES PER 100 WORDS SPOKEN FOR 4-YEAR-OLD CAUCASIAN AND ALASKA NATIVE CHILDREN

\begin{tabular}{l|ccc|ccc}
\hline \hline \multirow{2}{*}{$\begin{array}{c}\text { Disfluency } \\
\text { Type in } \\
\text { Rank Order }\end{array}$} & \multicolumn{2}{|c|}{ Alaska Native } & \multicolumn{3}{|c}{ Caucasian } \\
\cline { 2 - 7 } & Total & $\overline{\mathrm{x}}$ & S.D. & Total & $\overline{\mathrm{x}}$ & S.D. \\
$\begin{array}{l}\text { Interjection } \\
\text { Word }\end{array}$ & 31.00 & 1.82 & 1.57 & 45.00 & 2.65 & 1.55 \\
$\begin{array}{l}\text { Repetition } \\
\text { Revision- }\end{array}$ & 21.00 & 1.24 & 0.97 & 20.33 & 1.19 & 1.20 \\
$\begin{array}{l}\text { Incomplete } \\
\text { Phrase }\end{array}$ & 21.00 & 1.24 & 1.22 & 12.00 & 0.71 & 0.50 \\
$\begin{array}{l}\text { Phrase } \\
\text { Repetition }\end{array}$ & 9.00 & 0.53 & 0.62 & 8.67 & 0.51 & 0.54 \\
$\begin{array}{l}\text { Part-Word } \\
\text { Repetition } \\
\begin{array}{l}\text { Disrhythmic } \\
\text { Phonation }\end{array}\end{array}$ & 4.67 & 0.27 & 0.38 & 6.33 & 0.37 & 0.35 \\
$\begin{array}{l}\text { Intrusive } \\
\text { Schwa }\end{array}$ & 3.00 & 0.18 & 0.41 & 1.00 & 0.06 & 0.17 \\
$\begin{array}{l}\text { Tense } \\
\text { Pause }\end{array}$ & 0.00 & 0.00 & 0.00 & 0.67 & 0.04 & 0.11 \\
& 0.00 & 0.00 & 0.00 & 0.00 & 0.00 & 0.00 \\
$\begin{array}{l}\text { Total } \\
\text { Disfluency }\end{array}$ & 89.00 & 5.27 & 3.27 & 94.00 & 5.53 & 2.30 \\
\hline
\end{tabular}


The total frequency of disfluency in the current study (as was shown in Table $V$ ) was markedly lower in mean frequency of disfluency for 4-year-olds than the Haynes and Hood (1977), Wexler and Mysak (1982), and Wexler (1982) studies (see Table I, p. 37). Haynes and Hood (1977) reported a total disfluency mean of 7.04 per 100 words with a standard deviation of 2.90. Wexler and Mysak (1982) and Wexler (1982) reported a total disfluency mean of 9.10 per 100 words with a standard deviation of 3.20. There was no statistically significant difference in frequency of total disfluency between Caucasian and Alaska Native 4-year-old children in this study (see Table II, p. 41, and Table III, p. 43).

The second question posed in this study was: Do 4year-old Alaska Native children exhibit a greater frequency of specific disfluencies than 4-year-old caucasian children? An analysis of variance F-test revealed no statistically significant difference in frequency of specific disfluencies between the Caucasian and Alaska Native children at the .05 significance 1evel. The means and standard deviations for the frequencies of the eight disfluency types were reported in Table $\mathrm{V}$.

The Alaska Native children demonstrated a mean of 1.82 interjections per 100 words and a standard deviation of 1.57 , whereas the Caucasian children demonstrated a mean of 2.65 and a standard deviation of 1.55 .

Children from the Alaska Native group exhibited a mean of 0.27 for part-word repetition with a standard deviation of 
0.38 while the Caucasian children showed a mean of 0.37 and a standard deviation of 0.35 .

The Alaska Native children showed a mean of 0.00 for intrusive schwa with a standard deviation of 0.00 and the Caucasian children demonstrated a mean of 0.04 with a standard deviation of 0.11 .

Alaska Native children showed a mean of 1.24 for revision-incomplete phrase while the mean for the Caucasian children was 0.71 . Alaska Native children demonstrated a higher variability of revision-incomplete phrase as evidenced by a standard deviation of 1.22 , whereas the Caucasian children showed more of a consistency of disfluencies as reflected by a standard deviation of 0.50 .

Children from the Alaska Native group had a mean of 0.18 for disrhythmic phonation while the Caucasian group showed a mean of 0.06 . The Alaska Native group again demonstrated a higher variability of disrhythmic phonations as evidenced by a standard deviation of 0.41 while the Caucasian children demonstrated more of a consistency of disfluencies as reflected by a standard deviation of 0.17 .

With regard to word repetition, phrase repetition, and tense pause, the Alaska Native 4-year-old children and the Caucasian 4-year-old children exhibited nearly the same mean scores of 1.24 vs. $1.20,0.53$ vs. 0.51 , and 0.00 vs. 0.00 respectively. Standard deviations shown were 0.94 vs. 0.84, 0.61 vs. 0.53 , and 0.00 vs. 0.00 respectively. 
The third question posed by this study was: Do 4-yearold Caucasian and Alaska Native children exhibit a higher frequency of low risk disfluency types (word repetition, phrase repetition, interjection, and revision-incomplete phrase) when compared to high risk disfluency types (partword repetition, disrhythmic phonation, tense pause, and intrusive schwa)? Young (1984) states that type of disfluency is probably the major factor in judging speech behavior to be stuttering, however, some disfluencies are not as important as other disfluency types.

Revision, interjection, and word repetition are considered low risk disfluency types and were among the top four highest ranking disfluencies noted in the three prior comparable studies for 4-year-old children (Haynes and Hood, 1977; Wexler and Mysak, 1982; and Wexler, 1982). The results of the current study were consistent with these studies. Also, in these related studies part-word repetition, disrhythmic phonation, and tense pause were among the four least occurring disfluencies. The findings of the current study are consistent with these recent investigations. Except for the high occurrence of tense pause found in Wexler and Mysak (1982) and Wexler (1982), part-word repetition, disrhythmic phonation, and tense pause were relatively infrequent in the speech of normal 4-year-olds.

Two meaningful outcomes need to be considered. One, in the speech of normal 4-year-old children, part-word repetition, disrhythmic phonation, tense pause, and intrusive 
schwa appear to have occurred infrequently. Two, the findings of this study, along with previous investigations, suggest that when part-word repetition, disrhythmic phonation, and intrusive schwa increase in frequency of occurrence, they should be considered as critical indicators of incipient stuttering.

The distributional variability of the two samples reported under descriptive statistics prompt conjecture and is worthy of some discussion. The first, second, and third quartiles of the Alaska Native children appear to have lower quartile means of disfluencies than the Caucasian control group, which leads this investigator to review the possible effect of different cultures on fluency. One possible answer as to why the Alaska Native children appear to have lower quartile means in the first, second, and third quartiles is chance. If more subjects were included in the study perhaps the gap between the Alaska Natives and Caucasian children would fill in, leaving similar disfluency rates. A second possible reason for the difference in frequency between the two groups could involve the concept of "soft culture." The first, second, and third quartiles of Alaska Native children coincides with the concept of "easy" societies to which the Alaska Native subjects in the study belong.

The high frequency of disfluency in the fourth quartile of Alaska Native subjects, the concentration of high risk disfluency types in the quartile, and the predominance of Alaska Native to Caucasian children in the fourth quartile 
causes one to wonder how homogeneous the group of Alaska Native children is, and if there isn't something suggested that these may not be representative of Alaska Native children. One possible explanation for this distribution is chance. If the study was done again and/or with greater numbers of subjects the Alaska Native distributional patterns could result in a pattern more closely resembling the caucasians. Second, pressures caused by co-mingling with Caucasians could have an effect on the fluency rates of Alaska Native children. According to Fienup-Riordan (1982) the Alaska Native English speaker is accustomed to longer and more frequent pauses in conversation than Caucasian English speakers. When speaking to Caucasian speakers the Alaska Native possibly could feel greater pressure to fill in silent periods, resulting in greater disfluency.

Third, Johnson reports a distributional overlap in which $20 \%$ of the nonstutterers exceeded $30 \%$ of the stutterers in respect to total number of disfluencies (Bloodstein, 1987). The Alaska Native group, in the fourth quartile, could just be representative of this grey area. Lastly, the Alaska Native children in the sample could be incipient stutterers. The fourth quartile of Alaska Natives display both high frequency of disfluencies and a high concentration of high risk disfluencies which are indicative of incipient stuttering and not found in the remaining three quartiles. 
CHAPTER V

SUMMARY AND IMPLICATIONS

SUMMARY

Normative data on normal disfluency of Alaska Native children appears to be needed and without normative data it is difficult to differentiate disorder from normal ethnic variability. The majority of disfluency research has been done on Caucasian children and it appears that there has not been research done to ascertain the appropriateness of using Caucasian normative data to assess disfluencies of Alaska Native children.

The purpose of this study was to compare the frequency of occurrence of specific speech disfluencies in 4-year-old Alaska Native children to those of 4-year-old Caucasian children. Specifically, eight disfluency types were investigated: part-word repetition, word repetition, phrase repetition, interjection, revision-incomplete phrase, disrhythmic phonation, tense pause, and intrusive schwa. The questions addressed in the study were:

1. Do 4-year-old Alaska Native children exhibit a higher frequency of disfluencies than 4-year-old Caucasian children?

2. Do 4-year-old Alaska Native children exhibit a greater frequency of specific disfluencies, in 
terms of part-word repetition, word repetition, phrase repetition, interjection, revision-incomplete phrase, disrhythmic phonation, tense pause, or intrusive schwa than 4-year-old Caucasian children?

3. Do 4-year-old Alaska Native and Caucasian children exhibit a higher frequency of low risk disfluency types (word repetition, phrase repetition, interjection, and revision-incomplete phrase) when compared to high risk disfluency types (part-word repetition, disrhythmic phonation, tense pause, and intrusive schwa?

Thirty-four normal preschool children comprised the subjects of this study; 17 4-year-old Alaska Native children and 17 4-year-old Caucasian children. All the children were selected from the Kenai Peninsula and passed the selection criteria. Spontaneous speech samples were obtained and recorded from each of the subjects. Utilizing an analysis of variance, no statistically significant difference at the .05 level existed between the two racial groups.

The results yielded the following conclusions:

1. The 4-year-old Caucasian children did not exhibit a higher frequency of disfluencies than 4-year-old Alaska Native children.

2. There was no statistically significant difference in the frequency of occurrence of part-word repetition, word repetition, phrase repetition, interjection, revisionincomplete phrase, disrhythmic phonation, tense pause, or 
intrusive schwa exhibited by the two racial groups of normal children.

3. Both groups evidenced higher frequencies of low risk disfluency types (word repetition, phrase repetition, interjection, and revision-incomplete phrase) when compared to high risk disfluency types (part-word repetition, disrhythmic phonation, tense pause, and intrusive schwa).

The results of the current study indicate that interjection, revision-incomplete phrase, word repetition, and phrase repetition are the most common types of disfluencies occurring in the speech of 4-year-old Alaska Native and Caucasian children. Part-word repetition, disrhythmic phonation, tense pause, and intrusive schwa were the least frequently occurring types of disfluencies observed in Alaska Native and Caucasian 4-year-old children. However, there was a subgroup of Alaska Native children in the fourth quartile who were markedly more disfluent and their speech accounted for most of the high risk types of disfluencies found in the total sample of Alaska Natives.

\section{IMPLICATIONS}

The results of this study indicate that the use of normative data on Caucasians may be used in the differential diagnosis of Alaska Native children.

The results also provide information on the normal disfluencies observed in the speech of 4-year-old Alaska Native and Caucasian children. This data can be especially useful 
to speech and language pathologists who must make differential diagnosis between the normally disfluent child and the child who is an incipient stutterer. The findings of this study lend support to the guidelines provided by Adams (1977), Curran and Hood (1977), Curlee (1980), Hedgeman and Hartman (1979), Riley and Riley (1979), Yairi and Lewis (1984), and Van Riper (1982). Along with previous studies the results of the current study suggest that when the frequency of occurrence of disrhythmic phonation, part-word repetition, tense pause, and intrusive schwa increase, they should be considered as indicators of incipient stuttering. Finally, since most of the Alaska Natives were quite fluent and those more disfluent members accounted for most of the high risk disfluency elements, it would be advisable to follow such children carefully.

\section{$\underline{\text { Research }}$}

Further research is needed on normal disfluencies in Alaska Native children in order to replicate findings and establish normative guidelines. Present study excluded, it appears that normative fluency data on Alaska Native children is nonexistent.

When rank ordered from most to least fluent the lower $75 \%$ of the Alaska Native children are less disfluent than the Caucasian children. In future studies the possible relationship between this more fluent group and the "soft culture" aspects of the Alaska Natives should be considered. 
The possibility of an in-risk subgroup (top 25\%) of Alaska Native children could also be considered in future research.

Last, future research could consider "Westernization" and its effects on the fluency of Alaska Native children. The same video recordings used in the present study could be reanalyzed as to rate of speech and pause time in the Alaska Native children. It would be interesting to see if the top $25 \%$ in frequency of disfluency of Alaska Native children produced speech at a rate more consistent with the Caucasian subjects. 
Adams, M. R. (1977). A clinical strategy for differentiating the normally nonfluent child and the incipient stutterer. Journal of Fluency Disorders, 2, 141-148.

(1980). The young stutterers: diagnosis, treatment and assessment of progress. Seminars in Speech, Language, and Hearing, 1, 289-299.

Andrews, G., Craig, A., Feyer, A., Hoddinott, S., Howie, P., and Neilson, M. (1983). Stuttering: a review of research findings and theories circa 1982. Journal of Speech and Hearing Disorders, 48, 226-246.

Bjerkan, B. (1980). Word fragmentations and repetitions in the spontaneous speech of 2- to 6-year-old children. Journal of F1uency Disorders, 5, 137-148.

Bloodstein, 0. (1960a). The development of stuttering: I. Changes in nine basic features. Journal of Speech and Hearing Disorders, 25, 219-237.

(1960b). The development of stuttering: II. Developmental phases. Journal of Speech and Hearing Disorders, $25,366-376$.

(1981). A handbook on stuttering. 3rd ed. Champaign-Urbana: University of Illinois Press.

(1987). A handbook of stuttering. 4 th ed. Champaign-Urbana: University of I1linois Press.

Bloodstein, O. and Grossman, M. (1981). Early stutterings: some aspects of their form and distribution. Journal of Speech and Hearing Research, 24, 298-302.

Boehmler, R. (1958). Listener responses to non-fluencies. Journal of Speech and Hearing Research, 1, 123-141.

Branscom, M., Hughes, J., and Oxtoby, E. (1955). In W. Johnson (ed.), stuttering in children and adults. Minneapolis: University of Minnesota Press.

Christianson, P. (1987). Disfluencies in normal three and five year old male children. Masters thesis, Portland State University. 
Culp, D. M. (1984). The preschool fluency program. In M. Peins (ed.), Contemporary approaches to stuttering therapy. Boston, Little, Brown and Company.

Curlee, R. (1980). A case selection strategy for young dysfluent children. Seminars in Speech, Language, and Hearing, $1,277-287$.

Curran, M. F. and Hood, S. B. (1977). The effect of instructional bias on listener ratings of specific fluency tapes in children. Journal of Fluency Disorders, $3,181-186$.

Davis, D. (1939). The relationship of repetitions in the speech of young children to certain measures of language maturity and situational factors: Part I. Journal of Speech Disorders, 4, 303-318.

DeJoy, D. and Gregory, H. (1985). The relationship between age and frequency of dysfluency in preschool children. Journal of Fluency Disorders, 10, 107-122.

Egland, G. (1939). The relationship of repetitions in the speech of young children to certain measures of 1anguage maturity and situational factors: Part I. Journal of Speech Disorders, 4, 303-318.

(1955). In W. Johnson (ed.), Stuttering in children and adults. Minneapolis: University of Minnesota Press.

Emerick, L. and Hatten, J. (1979). Diagnosis and evaluation in speech pathology. Englewood Cliffs, NJ: PrenticeHa11, Inc.

Fienup-Riordan, A. (1980) Method: Alaskan perspectives. Fairbanks: University of Alaska/Fairbanks Press.

Floyd, S. and Perkins, w. (1974). Early syllable dysfluency in stutterers and nonstutterers: a preliminary report. Journal of Communication Disorders, 7, 279-282.

Freedman, D. (1983). Margaret Mead and Samoa: and unmaking of an anthropological myth. Harvard University Press.

the making Cambridge:

Gregory, H. and Hill, D. (1980). Stuttering therapy for children. Seminars in Speech, Lanquage, and Hearing, 1, $351-363$.

Haynes, W. and Hood, S. (1977). Language and dysfluency variables in normal speaking children from discrete chronological age groups. Journal of Fluency Disorders, 2, 57-74. 
Hedgeman, M. and Hartman, D. (1979). Factors affecting judgments of fluency: I. Interjections. Journal of Fluency Disorders, 4, 1-11.

Huffman, E. and Perkins, W. (1974). Dysfluency characteristics identified by listeners as "stuttering" and "stuttered." Journal of Communication Disorders, 7, 89-96.

Johnson, L. (1980). Facilitating parental involvement in therapy of the dysfluent child. Seminars in Speech, Language, and Hearing, 1, 31-39.

Johnson, W. (1942). The study of the onset and development of stuttering. Journal of Speech Disorders, 7, 251257 .

(1955). A study of the onset of stuttering. In W. Johnson (ed.), Stuttering in children and adults. Minneapolis: University of Minnesota Press.

(1959). The onset of stuttering. Minneapolis: University of Minnesota Press.

(1961). Measurement of oral reading and speaking rate and dysfluency of adult male and female stutterers and nonstutterers. Journal of Speech and Hearing Disorders Monograph Supplement, 7, 1-20.

(1972). In L. Emerick (ed.), An analysis of stuttering. Danville, IL: The Interstate Printers and Publishers, Inc.

Kidd, K. (1983). Can recovery from stuttering be considered a genetically milder subtype of stuttering? Behavior Genetics, 13, 129-139.

(1984). In R. Curlee (ed.), Nature and treatment of stuttering: new directions. San Diego: College Hi11 Press.

Leavitt, R. (1974). The Puerto Ricans. Tuscon: The University of Arizona Press.

Leith, w. (1986). In K. O. St. Louis (ed.), The atypical stutterer. New York: Academic Press, Inc.

Lemert, E. (1972). In L. Emerick (ed.), An analysis of stuttering. Danville, IL: The Interstate Printers and Publishers, Inc. 
Lingwal1, J. B. and Bergstrand, G. G. (1979). Perceptual boundaries for judgments of "normal," "abnormal," and "stuttered" prolongations. Journal of the American Speech and Hearing Association, 21, 733 .

McDearmon, J. (1968). Primary stuttering at the onset of stuttering: a re-examination of data. Journal of Speech and Hearing Research, 11, 631-637.

Metraux, R. (1950). Speech profiles of the preschool child 18 to 54 months. Journal of Speech and Hearing Disorders. $15,37-53$.

Meyers, S. (1986). Qualitative and quantitative differences and patterns of variability in disfluencies emitted by preschool stutterers and nonstutterers during dyadic conversations. Journal of Fluency Disorders, 11, 293306 .

Muma, J. (1971). Syntax of preschool fluent and disfluent speech: a transformational analysis. Journal of Speech and Hearing Research, 14, 428-441.

Panelli, C., McFarlane, S., and Shipley, K. (1978). Implications of evaluating and intervening with incipient stutterers. Journal of Fluency Disorders, 3, 41-50.

Perkins, W. (1971). Speech pathology: an applied behavioral science. St. Louis: Mosby.

Pindzola, R. H. and White, D. T. (1986). A protocol for differentiating the incipient stutterer. Language, Speech, and Hearing Services in Schools, $17,1-15$.

Riley, G. (1972). Stuttering severity instrument for children and adults. Journal of Speech and Hearing Disorders, $37,314-320$.

Riley, G. and Riley, J. (1979). A component model for diagnosing and treating children who stutter. Journal of Fluency Disorders, 4, 279-293.

Sanders, E. (1961). Reliability of the Iowa speech disfluency test. Journal of Speech and Hearing Disorders Monograph supplement, $7,21-30$.

(1963). Frequency of syllable repetition and stuttering judgments. Journal of Speech and Hearing Disorders, $6,19-30$. 
Shapiro, A. and Decicco, B. (1982). A relationship between normal dysfluency and stuttering: an old question revisited. Journal of Fluency Disorders, 7, 109-121.

Van Riper, C. (1963). Speech correction: principles and methods. 4th ed. Englewood Cliffs, NJ: PrenticeHa11, Inc.

(1971). The nature of stuttering. Englewood Cliffs, NJ: Prentice-Hall, Inc.

Wexler, K. (1982). Developmental disfluency in 2-, 4-, and 6 -year-old boys in neutral and stress situations. Journal of Speech and Hearing Research, 25, 229-234.

Wexler, K. and Mysak, E. (1982). Disfluency characteristics of 2-, 4-, and 6-year-old males. Journal of Fluency Disorders, 7, 37-46.

Williams, D. E. and Kent, L. R. (1958). Listener evaluations of speech interruptions. Journal of Speech and Hearing Research, 1, 124-131.

Williams, D., Silverman, F., and Kools, J. (1968). Disfluency behavior of elementary school stutterers and nonstutterers: $10 \mathrm{ci}$ of instances of disfluency. Journal of Speech and Hearing Research. 12, 308-318.

Wingate, M. (1962a). Evaluation and stuttering: Part I. Speech characteristics of young children. Journal of Speech and Hearing Disorders, 27, 106-115.

(1962b). Evaluation and stuttering: Part II. Environmental stress and critical appraisal of speech. Journal of Speech and Hearing Research, 27, 244-257.

(1964). A standard definition of stuttering. Journal of Speech and Hearing Disorders, 29, 197-201.

Yairi, E. (1981). Disfluencies of normally speaking twoyear-old children. Journal of Speeh and Hearing Research, 24, 490-495.

Yairi, E. and Clifton, N. (1972). Disfluent speech behavior of preschool children, high school seniors, and geriatic persons. Journal of Speech and Hearing Research, $15,714-7 \overline{19}$.

Yairi, E. and Lewis, B. (1984). Disfluencies at the onset of stuttering. Journal of Speech and Hearing

Research, $27,15 \overline{4-159 .}$ 
Young, M. (1961). Predicting ratings of severity of stuttering. Journal of Speech and Hearing Disorders,

Monograph Supplement, 7, 31-51.

(1975). Onset, prevalence, and recovery from stuttering. Journal of Speech and Hearing Disorders, $40,49-58$.

(1984). In R. Curlee (ed.), Nature and treatment of stuttering: new directions. San Diego: College Hill Press. 
APPENDIX A

LETTER OF INTRODUCTION TO PARENTS OR CAREGIVER

Dear

I am a graduate student in Speech and Language Pathology conducting a study on the different types of normal disfluencies in preschool children's speech.

I would like to videotape your child during 15 minutes of play and conversation. This would be done at a time that is convenient for you. Before the videotaping session I would like to meet with you and your child, at your home or other satisfactory location. During this time I will tape record a short conversation with your child. You will also be asked to complete a short questionnaire about your child's speech and language development, medical history, and family history.

You or your child's name will not be used in reporting the results. The videotapes will only be available to authorized personnel at the University.

If you are willing to participate in the study, please complete the form enclosed with this letter and either mail it back in the self-addressed, stamped envelope or call 283-7410 and leave a message. After I hear from you I will call you to schedule an appointment. Please call me if you have any questions. I would greatly appreciate your cooperation.

If you have any questions as a result of this study, please contact Robert C. Holloway, Grants and Contracts, 303 Cramer Hall, Portland State University, 1-800-547-8887.

Sincerely,

Mrs. Annette o'Connell 


\section{APPENDIX B \\ FORM INDICATING WILLINGNESS TO PARTICIPATE}

Date

Mrs. O'Connell,

[ ] I am willing to participate in the study. Parent's Name

Child's Name

Date of Birth

Message or Home Phone

[ ] I am not willing to participate in the study. Parent's Name

Child's Name 
APPENDIX C

DEMOGRAPHIC QUESTIONNAIRE AND CONSENT FORM

Child's Name Nickname

Birthdate Age

1. Is the primary language spoken in your home English?

Yes No

2. Does your child speak another language? Yes If so, what language?

3. List the children and adults living in your home. NAMES AGE RELATIONSHIP TO CHILD

4. Has your child had an ear infection within the last six months?

Yes No

5. Has your child ever been diagnosed as demonstrating any of the following:

Developmental delay

Neurological impairment

Hearing loss

Mental retardation

Orthopedic or physical handicap

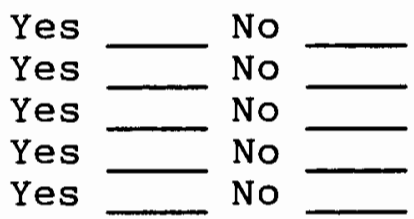

When did your child say his first word?

What was your child's first word?

When did your child first walk?

When was your child toilet trained?

Describe how your child learned to talk compared to other children in your family. 
Early_ Late __ Slow ___ Easy __ Hard

6. Has your child ever attended school? Yes No If so, where?

How long has your child attended school?

7. Has your child ever received speech therapy for stuttering?

Yes No

8. Is your child able to concentrate on a task for 15 minutes?

Yes No

9. What is your child's ethnic background?

Is your child 25 percent or more Alaska Native? Yes No

I hereby give my permission for my child to participate in this study. My child may attend a videotaping session and participate in the above mentioned evaluation at an agreed upon date and time.

I understand I may withdraw my permission at any time during this study without a penalty. 


\section{APPENDIX D}

\section{LIST OF STIMULI}

\section{TOYS}

2 telephones

2 cars

1 wind-up toy

1 puppet

2 dol1s

Tea and plate sets

Fisher-Price Farm set

1 electric dog

2 dinosaurs

1 airplane

\section{QUESTIONS}

Who 1 ives at your house?

Tell me about them.

What is your bedroom like?

Do you have any pets?

Tell me about them.

What do you do to take care of a pet?

What do you do at school?

Tell me about your friends.

What did you do for your last birthday?

Tell me about your favorite TV show.

Tell me how to make a peanut butter and jelly sandwich.

\section{$\underline{\text { PROMPTS }}$}

Tel1 me more.

What else?

Why?

Mmm, hmmm.

Tell me about it.

Oh, WOW.

Pretend you are

I wonder if . . . 
APPENDIX E

RULES FOR CALCULATING 300 WORD SAMPLES

1. Contractions of a verb form and "not," such as "won't" and "can't" are counted as one word. Contractions of a noun or pronoun and a verb, such as "I'm" and "they're" are also counted as one word (Branscom et al., 1955).

2. Hyphenated words which must occur together to convey thought are scored as one word, such as "teeter-totter" (Branscom et al., 1955).

3. Nonsense syllables are not counted as words.

4. Interjections, such as "ah" and "um," and extraneous words such as "well" and "you know," are not included in the total word count. Interjections are referred to as "stallers" by Branscom et al. (1955).

5. For each instance of repetition, only the last complete form is included in the total word count. For example: "can-can-can" or "c-c-can" is counted as 1 word.

"I can go, I can go" is counted as 3 words.

6. For each instance of revision-incomplete phrase, all words are included in the total word count. Partwords are also counted in this instance when the production was intentionally revised. For example: "She I mean he ran ran away" is counted as 6 words. "You cacould do that" is counted as 6 words.

7. Isolated "yes," "yeah," and "no" responses are deleted from the total word count to prevent inflating the speech samples with single word utterances. "Yes," "yeah," or "no" followed immediately by another word or phrase, however, are retained (Yairi and Lewis, 1984).

8. Utterance segmentation should be based on terminal intonation contour, rising or falling.

9. Words that are used to initiate more than two utterances in succession and are not associated with meaningful text, are not included in the total word count. Examples: "Hey," "oh," "and." 
10. Words used to represent animal noises, such as "meow," "moo," or "oink" are only included in the total word count when used within phrases. Examples: "woof, woof" would not be counted. "The cow says moo" would be counted.

(Portland State University protocol.) 


\author{
APPENDIX F \\ RULES FOR IDENTIFYING DISFLUENCIES
}

1. The insertion of any nonidentical remark between identical remarks cancels the repetitions. This includes words such as "yes," "no," and personal names. For example: "Put it in the wagon, no, put it in the wagon," or "We won't go down. Watch. We won't go down."

2. A phrase repetition may occur as part of one response, or may involve the repetition of a total response. For example: "What are these things, what are these things?" or "what are these, what are these things?" (Branscom et al., 1955).

3. The calling of an individual's name over and over does not count as a repetition. For exmaple: "Mary, Mary, Mary!"

4. The absence of the definite or indefinite article does not cancel the response as a repetition, because of the difficulty of detecting it in rapid speech. For example: "You sleep in the doghouse, you sleep in the doghouse" (Branscom et al., 1955).

5. A neutral vowel interjected or any interjections between two utterances of a part-word repetition, word repetition, phrase repetition, or revision-incomplete phrase does not negate the disfluency. The neutral vowel is counted as an interjection. With or without the interjection, it is still an instance of disfluency. For example: "Are you, uh, are you going?" "Are you, uh, were you going to store?" (Johnson, 1961).

6. Repetition of words of one syllable, such as "I" and "a" is considered word repetition rather than syllable repetition (Branscom et a1., 1955).

7. Repetition of part of a contraction is considered a partword repetition. For example: "I-I-I'm."

8. Sounds made in imitation of motors, rushing water, etc., are not scored as repetitions, since the child is attempting to imitate a continuous sound (Branscom et al., 1955 ). 
9. Repetitions which are obviously part of a quotation are not scored as repetitions. For example: "Ba, ba, black sheep, have you any wool? Yes sir, yes sir, three bags full" (Branscom et al., 1955).

10. Repetitions that are definitely self-corrections as far as they involve a change of thought or word are not counted as repetitions but as revision-incomplete phrases. For example: "Thirth...thirty-four" (Branscom et al., 1955).

11. Repetitions of either meaningful or nonsensical syllables, words, or phrases for the apparent enjoyment of rhythm are not counted as repetitions. Due to the fact that this is a subjective judgment on the part of the investigator, the content will be the deciding factor.

12. Words that are repeated for emphasis are not counted as repetitions. Example: "very, very clean" (Johnson, 1961).

13. Extraneous sounds such as "um," "er," "hm," or words such as "well" and "you know" which are produced unintentionaliy within the flow of speech and are not part of the phrase or sentence are identified as interjections. No matter how many times an interjection is repeated during one instance, it is only credited as one interjection. Example: "Um-um, can I go to the store?" contains only one instance of interjection while, "uh, I went to the park and um-um, we saw some dogs" contains two instances of interjections.

14. Instances in which the content or grammar of a phrase or pronunciation of a word is modified are considered as revision-incomplete phrases. Example: "You go-you want to go to the store?" "My do-there's another car."

15. Audible or silent continuations of a sound or articulatory posture which interrupts the rhythmic phonations; broken words, hard attacks and sound prolongations are synonymous with disrhythmic phonations.

16. Tension existing between words, part-words, and interjections is identified as tense pause.

(Portland State University protocol.) 
APPENDIX G

CODING SYMBOLS

Part-word repetition

PWR

Word repetition

WR

Phrase repetition

PhR

Interjection

I

Revision-incomplete phrase

RIP

Disrhythmic phonation

DP

T'ense pause

$\mathrm{TP}$

Intrusive schwa

IS 


\section{APPENDIX H}

\section{INSTRUCTIONS FOR SELECTION OF CONTENT TRANSCRIPTS FOR RELIABILITY TESTING}

Videotapes have been made of a child and an adult interacting in a free play situation. The children's conversations on these videotapes have been transcribed verbatim, and these transcripts are what you will be working from. You are responsible for extracting ten utterances from each of the five transcripts, and forming a content transcript for each one. A content transcript is defined as the basic information of an utterance provided by the child, omitting any type of disfluency such as: part-word repetitions (PWR), word repetitions (WR), phrase repetitions (PhR), interjections (I), revision-incomplete phrases (RIP), disrhythmic phonations (DP), tense pauses (TP), and intrusive schwa (IS), without the addition of any words that the child did not specifically speak. The following are specific guidelines that you need to use when developing these content transcriptions.

\section{GUIDELINES:}

1. Use utterances ten through nineteen from each of the five transcripts to form content transcripts.

2. Some utterances will be written verbatim in the content transcripts. Especially if the utterances are very short and do not include any disfluencies. The following are 
examples of utterances which would be included in the content transcripts word for word:
a. maybe
b. hi
c. just go away

3. Additional words should not be added to the utterances. Use only those words that are present in the transcripts.

4. Single utterances such as "yeah," "no," and "yes" that appear in the transcripts with nothing immediately following are to be omitted along with animal and machinery noises from the content transcription.

5. An unintelligible utterance would be labeled as an unintelligible utterance. If part of the episode is unintelligible, label the unintelligible segment but include the transcribed section in its complete form.

6. Disfluencies in the basic transcript should not be included in the content transcript. This includes: part-word repetitions, word repetitions, phrase repetitions, interjections, revision-incomplete phrases, disrhythmic phonations, tense pauses, and intrusive schwas. For exmple: "I-I-I have a dog" would be written "I have a dog" and "well, um, he is, um, he is running" would be written "He is running."

7. In transcribing revision-incomplete phrases into content utterances only include the most complete form of the 
episode. For example: "But I want-but $I$ don't want that one" would be written "But I don't want that one" and "Her name is Susan, no her name is sally" would be written "Her name is Sally."

EXAMPLES OF FULL TRANSCRIPTION AND CORRESPONDING CONTENT

\section{TRANSCRIPTION:}

\section{Ful1 Transcription}

This is it.

Uh ya, my brown shoes.

But $I$, but $I-I$ don't want any socks.

The sto-stove is hot.

c-can't-can't I go?

The (unintelligible)

How's-how's you?

\section{Content Transcription}

This is it.

My brown shoes.

But I don't want any socks.

The stove is hot.

Can't I go?

The (unintelligible)

How's you?

(Taken partially from PSU protocol.) 


\section{APPENDIX I}

\section{INSTRUCTIONS TO RELIABILITY JUDGES}

\section{GENERAL INSTRUCTIONS}

You will be given five partially complete transcripts. These transcripts contain 10 utterances which do not include any type of disfluency such as: part-word repetitions, word repetitions, phrase repetitions, interjections, revisionincomplete phrases, disrythmic phonations, tense pauses, and intrusive schwas. The transcripts contain only the content of the utterances. Remember that these transcripts may not be correct and that mistakes can be made in determining the content of the utterances. Listen to the entire utterance and see if you agree with all the words that have been transcribed and then add any additional words you hear along with all disfluencies.

The purpose of this reliability testing is to determine the investigator's accuracy at identifying part-word repetitions, word repetitions, phrase repetitions, interjections, revision-incomplete phrases, disrhythmic phonations, tense pauses, and intrusive schwas. The following are operational definitions : 
1. Word Repetition: unintentional repetitions of whole words, including words of one or more syllables. An interjection between word units does not negate the repetition. One repetition instance is credited even though a word is repeated several times.

Examples: "Let-let-let me go"

$$
\text { "I-Uh-I-uh-I want more" }
$$

2. Phrase Repetition: unintentional utterance of two or more words. Interjection between phrase units does not negate the repetition.

Examples: "What was, what was this"

"How can, uh, how can it go"

3. Part-word Repetition: unintentional repetitions of parts of words, either syllable or sound. One repetition instance is credited even though a sound or syllable unit may be repeated several times.

Examples: "d-d-dog"

$$
\begin{aligned}
& \text { "can-candy" } \\
& \text { "swim-uh-swimming" }
\end{aligned}
$$

4. Interjection: extraneous sounds such as "um," "uh," "er," "hm," or words such as "well" and "you know" which are inserted within the flow of speech and do not add meaning to a speaker's text. No matter how many times an interjection is repeated it is only credited as one interjection. 
Examples: "Uh-uh-uh, can I ride my bike?"

contains one instance of interjection.

"We11-well, he went to the uh-uh store"

contains two instances of interjections.

5. Revision-incomplete Phrase: instance in which alterations to a phrase are made in order to change the content, pronunciation, or grammar.

Examples: "He's got, he had some too"

"I ride, I rode my bike"

6. Disrhythmic Phonation: audible or silent continuation of a sound or articulatory posture which is of such excessive duration as to interrupt the rhythmic flow of speech. This disfluency occurs within words and includes broken words and prolongations.

Examples: "wa-a-1k"

$$
\text { "co-o-me home" }
$$

7. Tense Pause: tension judged to exist before or between part-words, and nonwords (interjections) when at the point in question there are barely audible manifestations of heavy breathing or muscular tightening.

8. Intrusive Schwa: the presence of the neutral schwa vowel intruding on the intended vowel.

Example: "tuh-tuh-table" 
PROCEDURES FOR TRANSCRIPTION AND IDENTIFICATION OF DIS-

\section{FLUENCIES.}

Five transcripts were randomly selected and prepared into content transcripts by an individual not involved with the study. Reliability raters were given these transcripts. The investigator then played the corresponding segment of the videotape that matched the content transcripts. All ten utterances were shown in their entirety to the reliability raters. The investigator then played the videotape segment again only showing the raters one utterance at a time. The raters were responsible for filling in all missing parts of the transcripts, including missing words and disfluencies. The raters identified the target disfluencies and were responsible for making any changes in the transcripts due to errors made by the individual selecting content transcripts. The raters were allowed to review the utterances when requested. There was no talking or discussion during reliability testing except when a request was made to review an utterance.

The following rules were used when transcribing and identifying disfluencies:

1. Raters were responsible for the identification of part-word repetitions, word repetitions, phrase repetitions, interjections, revision-incomplete phrases, dischythmic phonations, tense pauses, and intrusive schwas.

2. Identification of disfluencies by encircling the following notations above the disfluency: 
PWP: part-word repetition

WR: word repetition

PhR: phrase repetition

I : interjection

RIP: revision-incomplete phrase

DP : disrhythmic phonation

TP: tense pause

IS: intrusive schwa

3. Any interjection between two utterances of a partword repetition, word repetition, phrase repetition, or revision-incomplete phrase does not negate the repetition.

4. Interjection repetitions were not counted as either part-word or word repetitions.

5. No matter how many units of part-word, word, or phrase repetitions occurred, only one was credited as an instance of disfluency.

6. An utterance may have a combination of any of the eight disfluencies and therefore was credited as a separate disfluency.

7. Repetition of the first part of a contraction, such as "he-he's," was credited as part-word repetition since the contraction functions as a single word for the young child and was calculated as one word when determining the 300 word count for the initial transcripts.

TRAINING SESSION.

A training session was conducted by the investigator using the same procedures outlined above. The training 
session included practice identification of three different content transcripts. Differences were discussed with all members of the reliability team until everyone was in agreement over the disfluency identification. The reliability raters were $100 \%$ in agreement with each other before starting the reliability testing. 